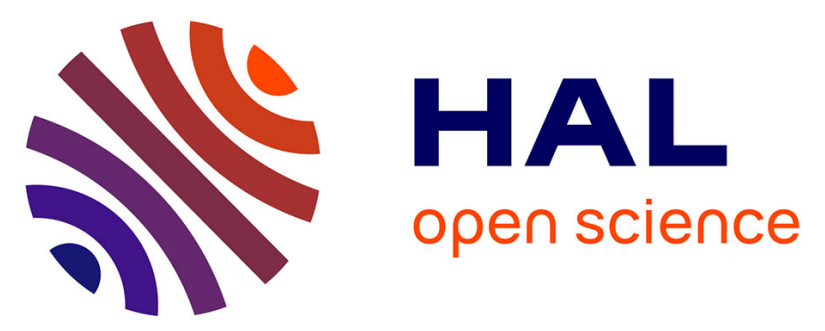

\title{
Origin and distribution of hydrocarbons and organic matter in the surficial sediments of the Sfax-Kerkennah channel (Tunisia, Southern Mediterranean Sea)
}

Hatem Zaghden, Marc Tedetti, Sami Sayadi, Mohamed Moncef Serbaji, Boubaker Elleuch, Alain Saliot

\section{To cite this version:}

Hatem Zaghden, Marc Tedetti, Sami Sayadi, Mohamed Moncef Serbaji, Boubaker Elleuch, et al.. Origin and distribution of hydrocarbons and organic matter in the surficial sediments of the SfaxKerkennah channel (Tunisia, Southern Mediterranean Sea). Marine Pollution Bulletin, 2017, 117 (1-2), pp.414 - 428. 10.1016/j.marpolbul.2017.02.007 . hal-01622004

\section{HAL Id: hal-01622004 \\ https://hal-amu.archives-ouvertes.fr/hal-01622004}

Submitted on 20 Apr 2018

HAL is a multi-disciplinary open access archive for the deposit and dissemination of scientific research documents, whether they are published or not. The documents may come from teaching and research institutions in France or abroad, or from public or private research centers.
L'archive ouverte pluridisciplinaire HAL, est destinée au dépôt et à la diffusion de documents scientifiques de niveau recherche, publiés ou non, émanant des établissements d'enseignement et de recherche français ou étrangers, des laboratoires publics ou privés. 


\section{Origin and distribution of hydrocarbons and organic matter in the surficial sediments of}

the Sfax-Kerkennah channel (Tunisia, Southern Mediterranean Sea)

Hatem Zaghden ${ }^{\mathrm{a}, \mathrm{b}^{*}}$, Marc Tedetti ${ }^{\mathrm{c}}$, Sami Sayadi ${ }^{\mathrm{b}}$, Mohamed Moncef Serbaji ${ }^{\mathrm{d}}$, Boubaker Elleuch $^{\mathrm{e}}$, Alain Saliot ${ }^{\mathrm{a}}$

a Laboratoire d'Océanographie et du Climat; Expérimentation et Approches Numériques LOCEAN, UMR CNRS 7159, CNRS/IRD/UPMC/MNHN, Université Pierre et Marie Curie, Case courrier 100, 4 Place Jussieu, 75252 Paris Cedex 05, France

${ }^{\mathrm{b}}$ Laboratoire des Bioprocédés Environnementaux, Pôle d'Excellence Régional AUF (PERLBP), Centre de Biotechnologie de Sfax, BP, 1177, 3018 Sfax, Tunisia

${ }^{\mathrm{c}}$ Aix Marseille Université, CNRS/INSU, Université de Toulon, IRD, Mediterranean Institute of Oceanography (MIO) UM 110, 13288, Marseille, France

${ }^{\mathrm{d}}$ Study and management of coastal and urban environments, National School of Engineers of Sfax, University of Sfax, Soukra, 3038 Sfax, Tunisia

${ }^{\text {e }}$ Laboratoire Eau-Energie-Environnement (Lab 3E), Université de Sfax, ENIS, BP W 3038, Sfax, Tunisia

* Corresponding author: hatem.zaghden@gmail.com; Phone: +216 74874 452; Fax: +21674874452

For submission to Marine Pollution Bulletin as a full length research paper

Final version, 20 January 2017 


\section{ABSTRACT}

We investigated the origin and distribution of aliphatic and polycyclic aromatic hydrocarbons (AHs and PAHs) and organic matter (OM) in surficial sediments of the SfaxKerkennah channel in the Gulf of Gabès (Tunisia, Southern Mediterranean Sea). TOC, AH and PAH concentrations ranged $2.3-11.7 \%, 8-174 \mu \mathrm{g} \mathrm{g}^{-1}$ sed. $\mathrm{dw}$ and $175-10,769 \mathrm{ng} \mathrm{g}^{-1}$ sed. $\mathrm{dw}$, respectively. The lowest concentrations were recorded in the channel (medium sand sediment) and the highest ones in the Sfax harbor (very fine sand sediment). AHs, PAHs and TOC were not correlated for most of the stations. TOC/N and $\delta^{13} \mathrm{C}$ values revealed a mixed origin of OM with both marine and terrestrial sources. Hydrocarbon molecular composition highlighted the dominance of petrogenic AHs and the presence of both petrogenic and pyrogenic PAHs, associated with petroleum products and combustion processes. This work underscores the complex distribution patterns and the multiple sources of OM and hydrocarbons in this highly anthropogenized coastal environment.

Keywords: Sediment, hydrocarbons, organic matter, Sfax, Gulf of Gabès, Mediterranean Sea. 


\section{Introduction}

The study of the composition of coastal sediments represents one of the main pathways to highlight the level and source of contamination within marine ecosystems. Indeed, sediments are receptacles for a wide variety of organic contaminants emitted from land and which reach the sedimentary layer through their adsorption onto particles in the water column. In addition, sediments may accumulate biogenic particulate material issued from surface waters and thus may provide fruitful information about autochthonous biological activity of marine ecosystems.

Hydrocarbons, including aliphatic hydrocarbons (AHs) and polycyclic aromatic hydrocarbons (PAHs), are abundant components of the organic material in coastal sediments (Volkman et al., 1992; Gogou et al., 2000), PAHs being among the most ubiquitous organic contaminants in the marine environment (Louati et al., 2001; Roose and Brinkman, 2005). AHs, which may be of biogenic or anthropogenic origin, consist of a series of resolved $n$ alkanes $(R)$ and of unresolved complex mixture (UCM). Their biogenic sources include terrestrial plant waxes, marine phyto- and zoo-plankton, bacteria and diagenetic transformations (Cripps, 1989; Rieley et al., 1991; Volkman et al., 1992; Wang et al., 1999; Mille et al., 2007), whereas their anthropogenic sources comprise essentially unburned petroleum/oils (Mazurek and Simoneit, 1984; Bouloubassi and Saliot, 1993; Wang et al., 1997; Readman et al., 2002; Zaghden et al., 2005).

Parent PAHs and their alkylated homologues (i.e. mono-, di-, tri- or tetra-methyl PAHs) may be also of biogenic or anthropogenic origin. PAHs are synthesized during the formation of oil (petrogenic PAHs), during the incomplete combustion of fossil fuels and biomass (pyrogenic PAHs) (Wang et al., 1999; Wurl and Obbard, 2004), and biologically produced in soils from woody plants, termites or from the microbial transformation of organic matter 
(Chen et al., 1998; Wilcke et al., 2002). Petrogenic PAHs consist of low molecular weight (LMW) 2-3 ring compounds with a high proportion of alkylated homologues, while pyrogenic PAHs comprise high molecular weight (HMW) 4-6 ring compounds with a low proportion of alkylated derivatives (Neff, 1979). PAHs are known to be harmful to living organisms, with reprotoxic, carcinogenic and mutagenic effects (Kennish, 1992). Therefore, they are recognized for a long time as highly priority contaminants by various international organizations: 8 PAHs are included in the list of the 45 priority regulated substances by the European Union (Official Journal of the EU 24/08/2013, Directive 2013/39/EU) and 16 PAHs are included in the list of 126 priority regulated substances by the US Environmental Protection Agency (US EPA, 40 CFR Part 423, Appendix A to Part 423).

Hence, hydrocarbons (AH and PAHs) in sediments may originate from numerous sources including petroleum inputs, incomplete combustion of fuels (PAHs), forest and grass fires (PAHs), biosynthesis by marine and terrestrial organisms, and early diagenetic transformation processes (UNEP/IOC/IAEA, 1992; Clark, 1997; Readman et al., 2002). Anthropogenic hydrocarbons are introduced into marine waters mainly via the direct discharge of crude oil and petroleum products during sea-based activities (spills from tankers, platforms and pipelines, ballast water discharge, drilling...) or via industrial and urban wastes (fuel combustion, traffic exhaust emissions, varied spills) routed by rivers, surface runoffs, effluents and the atmosphere (Wang et al., 1999; Wurl and Obbard, 2004; Dachs and Méjanelle, 2010). Thus, investigating the concentrations and molecular composition of hydrocarbons in surficial sediments allows for a better understanding of the levels and sources of anthropogenic contaminations and of the origin (marine versus terrestrial) of natural organic matter in coastal waters (Budzinski et al., 1997).

The Gulf of Gabès (Southeast Tunisia, Southern Mediterranean Sea) presents two major characteristics. First, it is one of the most productive coastal environments of the 
Mediterranean Sea due to nutrient availability and the main fishing area of the Tunisian coasts (Jabeur et al., 2001; Bel Hassen et al., 2009; D’Ortenzio and Ribera d'Alcalà, 2009; The Mermex group, 2011). Second, the Gulf of Gabès is submitted to very high anthropogenic pressures, especially around Sfax city, the second largest city in Tunisia and the one with the most important fishing and harbor activities. In this highly urbanized and industrialized area, organic contaminants are issued from a multitude of sources (Illou, 1999; Serbaji, 2000; Louati, 2003). However, the studies dealing with the assessment of the hydrocarbon levels in the surficial sediments of the Gulf of Gabès/Sfax coastal area remain few compared to those conducted in the Northwestern Mediterranean Sea. They have really begun in the 2000's with the first reports of concentrations in AHs (Louati et al., 2001; Zaghden et al., 2005; Elloumi et al., 2008; Aloulou et al., 2010; Amorri et al., 2011), in PAHs (Kessabi et al., 2013), and in both AHs and PAHs (Zaghden et al., 2007; 2014). Interestingly, the AH and PAH concentrations found in the surficial sediments of the Sfax coastal area are rather located in the upper range of those recorded for the whole Mediterranean Sea.

The main objectives of this study were 1) to determine the contents in several biogeochemical parameters $\left(\mathrm{C} / \mathrm{H} / \mathrm{N} / \mathrm{S}, \mathrm{TOC}, \mathrm{CaCO}_{3}\right.$ and $\left.\delta^{13} \mathrm{C}\right)$ and in hydrocarbons $(\mathrm{AHs}$ and PAHs) in surficial sediments of the Sfax-Kerkennah channel and to compare these contents to those recorded in other regions of the Mediterranean Sea. 2) To assess the spatial distribution of these parameters in relation to the Sfax-Kerkennah channel geomorphology/bathymetry and to examine the degree of correlation between these parameters, especially between TOC, AHs and PAHs. 3) To evaluate the origin (marine versus terrestrial versus anthropogenic) of organic matter and hydrocarbons regarding molecular/isotopic ratios and indices.

\section{Material and methods}




\subsection{Study area}

This study was conducted in the coastal area between the Sfax city and the Kerkennah Islands, in the Northern part of the Gulf of Gabès (Tunisia, Southern Mediterranean Sea) (Fig. 1). The Gulf of Gabès, located in the Southeast of Tunisia, extends from the city of Chebba $\left(35^{\circ} 14^{\prime} \mathrm{N}, 11^{\circ} 09^{\prime} \mathrm{E}\right)$ to the Tunisian-Libyan border $\left(33^{\circ} 10^{\prime} \mathrm{N}, 11^{\circ} 34^{\prime} \mathrm{E}\right)$ and shelters the Kerkennah Islands in the Northeast and Djerba Island in the Southeast. The climate in the Gulf of Gabès is arid to semiarid, i.e. dry (average annual precipitation: $210 \mathrm{~mm}$ ) and sunny with strong easterly winds (INM, 2008), resulting in a severe aeolian erosion and the transport of Saharan dusts into the sea (Jedoui, 1980; Bouaziz et al., 2003). The gulf is characterized by a wide continental shelf $(\sim 250 \mathrm{~km})$ with a very low slope and an important network of channels and wadis. Hence, its basin is very shallow, with in some areas, a water depth not exceeding $1 \mathrm{~m}$ over several kilometres. Also, in the Gulf of Gabès, the tide is semidiurnal and one of the highest in the Mediterranean Sea, with a maximum range of approximately $2.3 \mathrm{~m}$ at spring low tides (Sammari et al., 2006). The sediment of the gulf is rich in organic matter and principally composed of sand with a high density of plants (Ben Othman, 1973). The Gulf of Gabès is an important nursery for several species of fish and accounts for $65 \%$ of the Tunisian fish production (DGPA, 2010). These favourable geomorphologic and climatic conditions have led to the development of one of the most extensive marine habitats of seagrass

\section{Posidonia oceanica.}

Sfax $\left(34^{\circ} 43^{\prime} N, 10^{\circ} 46^{\prime} E\right.$; Fig. 1), with a population of about 730,000 inhabitants distributed over about 20,000 ha, represents the second largest city and the second economic pole in Tunisia. Sfax is heavily industrialized with important fishing and harbor activities. Its main industrial activity domains are phosphates, chemical products, textiles, olive oil, food, soap and paint. Therefore, the sources of pollution in the Sfax coastal zone are numerous: atmospheric depositions, ship traffic, fishery activities, rivers, wadis, wild landfills, municipal 
sewage effluents and industrial wastewaters, especially those coming from the storage of crude oil, phosphogypsum and olive oil wastes at the coast (Ben Mustapha et al., 1999; Louati et al., 2001). The Kerkennah Islands ( $34^{\circ} 42^{\prime} \mathrm{N}, 11^{\circ} 11^{\prime} \mathrm{E}$; Fig. 1), which include the two principal islands Gharbi and Chergui, are situated $\sim 20 \mathrm{~km}$ offshore Sfax. They have an area of $160 \mathrm{~km}^{2}$ and are low-lying being no more than $13 \mathrm{~m}$ above the sea level. These islands are characterized by a $-10 \mathrm{~m}$ isobath few kilometers away from the shoreline and by a lithology dominated by smooth rocks (Katlane et al., 2014). Since there is neither industrial activity nor urban concentration in the Kerkennah Islands, the latter are much less submitted to anthropogenic pressures than the Sfax coastal area.

The Sfax-Kerkennah channel is an underwater channel, Northeast-Southwest oriented, which cut the shelf at depths higher than $20 \mathrm{~m}$. It allows for conducting the ferry boat crossings Sfax-Kerkennah (Fig. 1). Bottom sediments are largely composed of sand, muddy sand and shell-sand with a high density of plants. This structure extends from the beaches up to about $20 \mathrm{~m}$ depth. Muddy sands are the most widespread sediment of the Sfax shelf. This sediment is the substrate of mixed Cymodocea and Posidonia meadows. In some places (southern Kerkennah), areas with gravel or concretions of calcareous algae are distinguished. At the Kerkennah islands, the shelf is characterized by the presence of sandy shoals.

\subsection{Sampling, storage, sieving and granulometric analysis of samples}

Twenty stations were sampled in January 2005 at low tide on board a vessel from the Fishing Professional Training Centre of Sfax. Stations were located along two transects: one between the North of Sfax - Sidi Mansour area (station R101) and the Kerkennah harbor (station R111), and the other one between the Kerkennah harbor and the Sfax harbor (station R201) (Fig. 1; Table 1). Stations R104-R107 and R203-R210, displaying depths from > 5 to $20 \mathrm{~m}$, were comprised within the Sfax-Kerkennah channel, whereas stations R101-R103, 
R108-R111, R201 and R202, with depths $<5$ m, were positioned outside the channel (Table 1). At each station, surficial sediments $(0-1 \mathrm{~cm})$ were collected by professional divers. Surficial sediments were transferred into pre-combusted $\left(450^{\circ} \mathrm{C}, 6 \mathrm{~h}\right)$ glass bottles and stored on board in the dark in the cold $\left(\sim 6^{\circ} \mathrm{C}\right)$.

Back in the laboratory, samples were immediately frozen at $-20^{\circ} \mathrm{C}$. They were maintained frozen for few days and then freeze dried. Afterwards, each sediment sample (200 g) was dry sieved sequentially during $30 \mathrm{~min}$, using an electric shaker, through twenty AFNOR standard stainless steel screens of mesh sizes ranging from $4 \mathrm{~mm}$ to $50 \mu \mathrm{m}$ (Aloulou et al., 2012). Before sieving, stainless steel forceps were used to remove vegetal fragments from sediment samples. The percentages of sediment mass corresponding to each particle size were determined. Grain Size Analyzer (GSA) software was used to establish granulometric curves and to derive the parameters describing the grain size distribution, i.e. the index of mean trend, expressed by the mean of the size $\left(\mathrm{M}_{\mathrm{z}}\right)$, and the index of classification, expressed by the standard deviation of the size $(\sigma) . M_{z}$ and $\sigma$ are given in unit $\phi$, where $\phi=-\log _{2} D / D_{0}$ ( $\mathrm{D}_{0}$ being a reference diameter and $\mathrm{D}$ the diameter of the particle in $\mathrm{mm}$ ) (Folk and Ward, 1957; Blott and Pye, 2001; Ghannem et al., 2011). All chemical analyses (hydrocarbons, elemental composition, organic carbon, calcium carbonate, $\delta^{13} \mathrm{C}$, see below) were performed on the fraction $<63 \mu \mathrm{m}$, which represents the fraction of silts and clays.

\subsection{Extraction, purification and GC-FID/MS analysis of hydrocarbons}

Sediment samples (around $5 \mathrm{~g}$ dry weight of the fraction $<63 \mu \mathrm{m}$ ) were transferred into a pre-combusted glass tube, in which were also added $30 \mathrm{ml}$ of a dichloromethane $\left(\mathrm{CH}_{2} \mathrm{Cl}_{2}\right) /$ methanol $\left(\mathrm{CH}_{3} \mathrm{OH}\right)(3: 1 \mathrm{v} / \mathrm{v})$ solvent mixture, deuterated (internal) standard mixtures ( $n-\mathrm{C}_{24}-d_{50}$ for AHs and p-terphenyl- $d_{14}$ for PAHs) and activated copper to remove sulphurs. Extraction was carried out in an ultrasonic bath for 15 min. The sediment was then 
isolated from the lipid extract by centrifugation (3500 rpm for $10 \mathrm{~min})$. The entire extraction procedure (ultrasounds and centrifugation) was repeated 3 times. The extracts (supernatants) were combined and concentrated with a rotary evaporator at $\mathrm{T}<30^{\circ} \mathrm{C}$, dried with magnesium sulphate and filtered on a pre-combusted glass fiber filter of porosity $4 \mu \mathrm{m}$. The remaining solvent was changed to $n$-hexane (Ke et al., 2004; Bouloubassi et al., 2006; Parinos et al., 2013).

Hexane-solubilised extracts were purified to separate AHs and PAHs (hydrocarbon fraction) from more polar compounds. The extracts were fractionated on a column (6 mm i.d.) filled with $400 \mathrm{mg}$ of silica gel (extra pure Merck 60), beforehand Soxhlet extracted with $\mathrm{CH}_{2} \mathrm{Cl}_{2}$, activated $1 \mathrm{~h}$ at $150{ }^{\circ} \mathrm{C}$ and partially deactivated with $4 \%$ water by weight. The $\mathrm{AH}$ fraction was first eluted with $3 \mathrm{ml} n$-hexane, followed by the elution of the PAH fraction with $9 \mathrm{ml}$ hexane/toluene $(9: 1 \mathrm{v} / \mathrm{v})$. Finally, purified extracts were concentrated to $150-200 \mu \mathrm{l}$ with a rotary evaporator and a gentle stream of nitrogen.

Analyses of hydrocarbons (AHs and PAHs) were performed with a Delsi DI 200 gas chromatograph coupled with a flame ionisation detector (GC-FID) (Perichrom, France) (Zaghden et al., 2007; 2014). The GC-FID was equipped with a DB-5 MS fused-silica capillary column $(30 \mathrm{~m} \times 0.25 \mathrm{~mm} \times 0.25 \mu \mathrm{m}, \mathrm{J} \& \mathrm{~W}$ Scientific, Agilent Technologies, USA) and used helium as a carrier gas at a flow rate of $1.5 \mathrm{ml} \mathrm{min}^{-1}$. The injector (used in splitless mode) and detector temperatures were 250 and $320^{\circ} \mathrm{C}$, respectively. The initial column temperature was held for $2 \mathrm{~min}$ at $60{ }^{\circ} \mathrm{C}$, next ramped at $25{ }^{\circ} \mathrm{C} \min ^{-1}$ (ramp 1) to $100{ }^{\circ} \mathrm{C}$ and then at $2{ }^{\circ} \mathrm{C} \min ^{-1}(\operatorname{ramp} 2)$ to a final temperature of $310^{\circ} \mathrm{C}$, which was held for $10 \mathrm{~min}$. With each set of samples to be analysed, $\mathrm{AH}$ and PAH calibration standards were run for peak identification and quantification. Compounds were identified mainly by their retention times. To confirm the structure of several hydrocarbons, some samples were also analysed using a HP 6890 gas chromatograph coupled with a HP 5973 MSD mass spectrometer (GC-MS) 
(Agilent Technologies, Wilmington DE, USA), equipped with a DB-5 MS fused-silica capillary column coated with 5\% phenyl methyl siloxane (Zaghden et al., 2007; 2014).

Helium was used as a carrier gas. The injector temperature and column temperature program were the same than those used for the GC-FID. GC-MS analyses were run in the electron impact mode at $70 \mathrm{eV}$ with a $0.6 \mathrm{scan} \mathrm{s}^{-1}$ time over a 50-550 atomic mass unit (amu) range resolution.

\subsection{Quality assurance and quality control of hydrocarbon analyses}

During the procedures described above, nitrile gloves were worn and care was taken to avoid contaminations. All the glassware was cleaned with ultrapure water (Milli-Q water from Millipore system, final resistivity: $18.2 \mathrm{M} \Omega \mathrm{cm}^{-1}$ at $25^{\circ} \mathrm{C}, \mathrm{pH} \sim 5$ ), combusted at $450{ }^{\circ} \mathrm{C}$ during $6 \mathrm{~h}$ and finally cleaned with $\mathrm{CH}_{3} \mathrm{OH}$ and $\mathrm{CH}_{2} \mathrm{Cl}_{2}$ before use. The precision glassware, which could not be baked, was cleaned in a bath of sulfochromic acid for at least $4 \mathrm{~h}$, and then rinsed with ultrapure water, $\mathrm{CH}_{3} \mathrm{OH}$ and $\mathrm{CH}_{2} \mathrm{Cl}_{2}$. All the (Teflon-lined) caps were wrapped with Teflon tape for the storage of samples. All organic solvents were of trace-analysis quality (Merck, Darmstadt, Germany) and were further distilled before use. Silica and magnesium sulphate were purified by soxhlet extraction with $\mathrm{CH}_{2} \mathrm{Cl}_{2}$ for $24 \mathrm{~h}$ and then dried in the oven.

Deuterated (internal) standards mixtures (04071, Fluka, and 47543-U, Supelco) were introduced before ultrasonic treatment to assess the recoveries of the analytical procedure (including extraction, evaporation and purification processes). The latter were on average > 75\% for the different AHs and PAHs investigated. Calibration (external) standards (04071, Fluka, and 47543-U, Supelco) as well as procedural and solvent blanks were run with each set of samples to check for contamination and for quantification. Calibration curves were constructed for all target hydrocarbons analysed except for the alkylated PAHs, which were 
quantified with their parent-compound calibration curves. For the different hydrocarbons, the detection limits ranged from 0.01 to $0.5 \mathrm{ng} \mathrm{g}^{-1}$. Instrumental reproducibility, evaluated from samples R110 and R207, was on average $\pm 10 \%$. All the concentration values, given in $\mathrm{ng} \mathrm{g}^{-1}$ (PAHs) or $\mu \mathrm{g} \mathrm{g}^{-1}$ (AHs) sediment dry weight (sed. dw), were blank- and recovery-corrected.

\subsection{Determination of individual hydrocarbons and molecular diagnostic ratios}

For AHs, we determined the concentrations of resolved $n$-alkanes $(R)$, including linear $n$-alkanes from $n$ - $\mathrm{C}_{15}$ to $n$ - $\mathrm{C}_{34}$ and two isoprenoids, pristane ( $\left.\mathrm{Pr}, \mathrm{C}_{19}\right)$ and phytane (Phy, $\left.\mathrm{C}_{20}\right)$, and the concentrations of UCM. We computed different ratios and indices allowing to distinguish biogenic AHs (issuing from biological activity) and petrogenic AHs (coming from uncombusted petroleum): 1) the $\mathrm{UCM} / R$ ratio as indicator of the presence of degraded petroleum products (when > 3-4) (Simoneit and Mazurek, 1982; Mazurek and Simoneit, 1984). 2) The Pr/Phy ratio as indicator of biogenic AHs (when $>>1$ ), even though values < 1 do not necessarily reflect the presence of petrogenic AHs (Cripps, 1989; Commendatore and Esteves, 2004; Cincinelli et al., 2008). 3) The $n-\mathrm{C}_{17} / \mathrm{Pr}$ and $n-\mathrm{C}_{18} / \mathrm{Phy}$ ratios as indicators of degraded (when < 1) or less degraded or relatively fresh AHs (when > 1) (Mille et al., 2007; Asia et al., 2009). 4) The carbon preference index, the ratio of odd to even carbon-numbered $n$-alkanes, in the ranges $n-\mathrm{C}_{15}-n-\mathrm{C}_{24}$ and $n-\mathrm{C}_{25}-n-\mathrm{C}_{34}\left(\mathrm{CPI}_{15-24}\right.$ and $\left.\mathrm{CPI}_{25-34}\right)$, which are indicators of crude oil/petrogenic AHs (when 1) or biogenic AHs (when $>>$ or $<<1$ ) (Eglinton and Hamilton, 1967; Rieley et al., 1991; Wang et al., 1999; Harji et al., 2008). 5) The terrigenous/aquatic ratio (TAR), the ratio between the concentrations of long-chain $n$ alkanes $\left(n-\mathrm{C}_{27}+n-\mathrm{C}_{29}+n-\mathrm{C}_{31}\right)$ to short-chain $n$-alkanes $\left(n-\mathrm{C}_{15}+n-\mathrm{C}_{17}+n-\mathrm{C}_{19}\right)$, as index of the relative importance of terrestrial (higher plants) and aquatic (algae, phyto-and zooplankton) materials (Bourbonniere and Meyers, 1996; Mille et al., 2007) (Table 2). 
Concerning PAHs, we investigated the concentrations of 17 PAHs: 12 parent PAHs, namely naphthalene (Nap), phenanthrene (Phe), anthracene (Ant), thiophene (Thi), fluoranthene (Flt), pyrene (Pyr), benzo[a]anthracene (BaA), chrysene (Chr), benzo[k]fluoranthene $(\mathrm{BkF})$, benzo[a]pyrene $(\mathrm{BaP})$, perylene $(\mathrm{Per})$ and benzo[g,h,i]perylene $(\mathrm{BgP})$, and 5 alkylated homologues, i.e. the sums of mono-, di- and tri-methyl compounds ( $\sum \mathrm{Me}$ ) of the five target compounds Nap, Phe, Ant, Pyr and Chr. Thi is a 1-ring sulfur heterocyclic compound. Naph and its alkylated homologues are 2-ring compounds. Phe, Ant and their alkylated homologues are 3-ring compounds. These 2-3 ring compounds represent low molecular weight (LMW) PAHs. Flt, Pyr, BaA, Chr and alkylated homologues of Pyr and Chr are 4-ring compounds. $\mathrm{BkF}, \mathrm{BaP}$ and Per are 5-ring compounds, whereas $\mathrm{BgP}$ is a 6-ring compound. These 4-6 ring compounds represent high molecular weight (HMW) PAHs. We determined several ratios allowing to differentiate petrogenic PAHs and pyrogenic PAHs (issuing from the incomplete combustion of fossil fuels), PAHs from fuel combustion and those from the combustion of grass, coal or wood, and PAHs from traffic emissions and PAHs from non-traffic emissions: $\sum \mathrm{LMW} / \sum \mathrm{HMW}, \sum \mathrm{MePhe} / \mathrm{Phe}, \sum \mathrm{MePyr} / \mathrm{Pyr}, \mathrm{Flt} / \mathrm{Flt}+\mathrm{Pyr}$ and BaP/BgP (Yunker et al., 2002; Brändli et al., 2008; Tobiszewski and Namieśnik, 2012; Katsoyiannis and Breivik, 2014) (Table 2).

\subsection{Analysis of $\mathrm{C} / \mathrm{H} / \mathrm{N} / \mathrm{S}$, TOC, $\mathrm{CaCO}_{3}$ and $\delta^{13} \mathrm{C}$}

Several parameters were measured on sub-samples of freeze-dried and homogenized sediments (fraction $<63 \mu \mathrm{m}$ ). Content in total carbon, hydrogen, nitrogen and sulphur $(\mathrm{C} / \mathrm{H} / \mathrm{N} / \mathrm{S})$ was determined using a SC-144 LECO Elemental Analyzer at combustion temperatures of $1050(\mathrm{C}, \mathrm{H}, \mathrm{N})$ or $1350{ }^{\circ} \mathrm{C}(\mathrm{S})$ in oxygen $(\mathrm{C}, \mathrm{H}, \mathrm{S})$ or helium $(\mathrm{N})$ atmosphere. For total organic carbon (TOC) determination, sediment sub-samples were acidified with $1 \mathrm{~N}$ $\mathrm{HCl}$ and oven dried at $60{ }^{\circ} \mathrm{C}$. This procedure (acidification and drying) was repeated twice in 
order to remove inorganic carbon. Then, sub-samples were run in the Elemental Analyzer the same way as for total carbon. Two replicates of each sample were run for these elemental analyses. Content in calcium carbonate $\left(\mathrm{CaCO}_{3}\right)$ was estimated as the difference between total carbon and TOC contents. Concentrations in $\mathrm{C}, \mathrm{H}, \mathrm{N}, \mathrm{S}$, TOC and $\mathrm{CaCO}_{3}$ are expressed in percentages (\%) for $1 \mathrm{~g}$ sed. $\mathrm{dw}$.

$\delta^{13} \mathrm{C}$, given in $\%$, is the ratio of stable isotopes ${ }^{13} \mathrm{C} /{ }^{12} \mathrm{C}$. It was determined on OC (acidified) sub-samples using the following formula: $\left[\left({ }^{13} \mathrm{C} /{ }^{12} \mathrm{C}\right)_{\text {sample }} /\left({ }^{13} \mathrm{C} /{ }^{12} \mathrm{C}\right)_{\text {standard }}-1\right] \mathrm{x}$ 1000, where $\left({ }^{13} \mathrm{C} /{ }^{12} \mathrm{C}\right)_{\text {standard }}$ corresponds to the isotopic ratio of the international standard Pee

Dee Belemnite (PDB), and $\left({ }^{13} \mathrm{C} /{ }^{12} \mathrm{C}\right)_{\text {sample }}$ to the isotopic ratio measurements of sediment subsamples conducted by using an elemental analyzer coupled to an isotopic ratio mass spectrometer (EA-IRMS).

\subsection{Statistical analyses}

Ocean Data View (ODV) software version 4.6.5 (Schlitzer, R., http://odv.awi.de, 2014.) was employed for the spatial representation of TOC; $\delta^{13} \mathrm{C}, R$ and PAH concentrations as well as $R /$ TOC and PAH/TOC ratios. The spatial interpolation/gridding of data was performed using Data-Interpolating Variational Analysis (DIVA) (Barth et al., 2010; Troupin et al., 2012). Pearson correlation matrices were performed using XLSTAT 2011.2.05 (Microsoft Excel add-in program). The significance threshold was set at $\mathrm{p}<0.05$.

\section{Results and discussion}

\subsection{Granulometry and content in $\mathrm{C} / \mathrm{H} / \mathrm{N} / \mathrm{S}, \mathrm{TOC}, \mathrm{CaCO}_{3}$ and $\delta^{13} \mathrm{C}$}

Mean grain size $\left(\mathrm{M}_{\mathrm{z}}\right)$ ranged from 4 to $3 \phi$ (i.e. $62.5-125 \mu \mathrm{m}$; very fine sand) in stations R104, R111, R201, from 3 to 2 ф (i.e. $125-250 \mu \mathrm{m}$; fine sand) in stations R101-R103, R106, 
R108-R110, R202, R210, and from 2 to $1 \phi$ (i.e. 250-500 $\mu$ m; medium sand) in stations R105, R107, R203-R209 (Table 3). The index of classification ( $\sigma$ ) was comprised between 2 and $1 \phi$ for all stations, which reflected poorly sorted sands (Table 3). Therefore, the granulometric distribution was closely related to the bathymetry and geomorphology of the Sfax-Kerkennah channel. The fact that sediments were essentially constituted of sand is in accordance with the hydrodynamic properties of this intertidal area where the combined action of waves and tide prevent the deposition of the finest fraction along with promoting a sandy facies (Aloulou et al., 2012). Apart from stations R104, R106 and R210, which were situated at the border of or within the channel, fine and very fine sands were found outside the channel, i.e. in the most coastal and the shallowest stations, including harbors (Fig. 1; Tables 1, 3). In contrast, medium sand was observed in the deepest stations, in the area where the channel is the widest. In this zone, fines particles, coming from the North-East South-West-oriented current, cannot reach the bottom and are transported further southward (Fig. 1; Tables 1, 3).

The content in C, H, N and S ranged from 7.9 (R202) to $14.6 \%$ (R201), from 0.57 (R202) to $1.91 \%$ (R201), from 0.19 (R203, R202) to $1.23 \%$ (R201) and from 0.10 (R107) to $1.33 \%$ (R201), respectively (Table 3). The highest percentages were thus recorded in the Sfax harbor (R201) and the lowest ones close to the Sfax harbor (R203, R202) or in the SfaxKerkennah channel (R107). The C content was comparable to that determined in surficial sediments of Moroccan coastal waters (Southern Mediterranean Sea), i.e. 1.3-15.1\% (Pavoni et al., 2003). In contrast, the $\mathrm{N}$ and $\mathrm{S}$ contents were much higher than those reported for these Moroccan waters or in the Todos os Santos Bay, Brazil (0.01-0.3 and < 0.01-1.3\%, respectively) (Pavoni et al., 2003; Venturini et al., 2004).

The TOC content varied between $~ 2.3$ (R203, R202) and 11.7\% in the Sfax harbor (R201) and, quite surprisingly, in the Sfax-Kerkennah channel (R107) (Table 3; Fig. 2a). High values of $\sim 7.2 \%$ were observed in the Kerkennah harbor (R111) and the Sfax- 
Kerkennah channel (R104) (Table 3; Fig. 2a). The TOC content determined here was higher than that found in the surficial sediments of the Northeastern $(0.02-2.4 \%)$ and Northwestern (0.35-6.2\%) Mediterranean Sea (Lipiatou and Saliot, 1991a; Benlahcen et al., 1997;

Kucuksezgin et al., 2013) and the Bizerte Lagoon (0.4-3.9\%) (Barhoumi et al., 2014). Nonetheless, it was lower than that recorded in the Abu Qir Bay (Egyptian coasts), where it reached up to $20 \%$ (El Deeb et al., 2007). Our quite high TOC concentrations were very likely related to the enhanced marine productivity (eutrophication) of this coastal area due to diverse nutrient inputs (Bel Hassen et al., 2009; D’Ortenzio and Ribera d'Alcalà, 2009; The Mermex group, 2011).

The TOC/N ratio ranged from 9.4 (R201) to 56.6 (R107) (Table 3), which was higher than that measured in the surficial sediments from the Northwestern Mediterranean Sea $(\sim 7)$ (Charles et al., 2012), the Northern Adriatic (3-37) (Guerra, 2012; Acquavita et al., 2014) and the Todos os Santos Bay, Brazil (8.8-27.6) (Venturini et al., 2004). The TOC/N ratio may provide information about the origin of organic matter. A high TOC/N ratio (> 20) reveals rather a terrestrial origin of organic matter due to the low $\mathrm{N}$ percentage in the higher vegetation (Muller, 1977; Emerson and Hedges, 1988; Meyers, 1994). On the other hand, a low TOC/N ratio (5-7) implies a marine origin (plankton or seaweeds) (Muller 1979; Monoley and Field, 1991; Meyers, 1994). In our case, TOC/N ratio was comprised between 9.4 (R201) and 18 (R110) for almost all the stations, which suggested a mixed origin with both autochthonous marine and terrestrial sources. For station R111 (22.3) and above all R107 (56.6), the high ratio was in favour of a dominance of the terrestrial origin of organic matter. The TOC/S ratio varied between 2.6 (R202) and 118.9 (R107) (Table 3) and was more important than that observed in Todos os Santos Bay (2.8-13.6) (Venturini et al., 2004). Except in station R202, the TOC/S ratio was > 2.8, which put forward the occurrence of oxic conditions in the surficial sediments of the Sfax-Kerkennah channel (Leventhal, 1983; Berner, 
1989). It is worth noting that the high TOC/N and TOC/S ratios observed in R107 were due to an elevated TOC content relative to low $\mathrm{N}$ and $\mathrm{S}$ concentrations (Table 3 ).

The content in $\mathrm{CaCO}_{3}$ was minimal $(\sim 40 \%)$ in the Sfax-Kerkennah channel (R104) and the Sfax harbor (R201), and maximal ( 95.6\%) on the Sidi Mansour-Kerkennah transect (R105, R108) (Table 3). This content was on average higher than that recorded in surficial sediments of Todos os Santos Bay, Brazil (0-93.2\%) (Venturini et al., 2004) and Athens coastal area, Greece (24-86.3\%) (Kapsimalis et al., 2014). The presence of $\mathrm{CaCO}_{3}$ in surficial sediments is related to marine organisms. In our case, the two mains contributors of $\mathrm{CaCO}_{3}$ would be benthic foraminifera and green seaweeds (Aloulou et al., 2012). The highest $\delta^{13} \mathrm{C}$ signature was found in R101 (-20.9\%o). It decreased from R101 to R107 (-25.1\%o) and increased from $\mathrm{R} 107$ to $\mathrm{R} 111\left(-22.2 \%\right.$ ). Then, the $\delta^{13} \mathrm{C}$ signature tended to decrease to reach $-25.5 \%$ in R203. It finally slightly increased towards R201 (-24.0\%o) (Table 3; Fig. 2b). Carbon isotopic ratio $\left(\delta^{13} \mathrm{C}\right)$ is useful to distinguish between marine and terrestrial sources of sedimentary organic matter. Marine organic matter typically has $\delta^{13} \mathrm{C}$ values between -22 and $-20 \%$, whilst terrestrial organic matter $\left(\mathrm{C}_{3}\right.$ land plants) has an average $\delta^{13} \mathrm{C}$ value of $-27 \%$ o (Meyer, 1994). It thus appears that our sediments displayed overall a mixed origin with a stronger marine fingerprint in stations R101-R103, R109 and R111 (Table 3; Fig. 2b).

\subsection{Concentrations in hydrocarbons, comparison with other regions of the}

\section{Mediterranean and Sediment Quality Guidelines}

Total $R$ concentration (sum of $n-\mathrm{C}_{15}$ to $n-\mathrm{C}_{34}+\mathrm{Pr}$ and Phy) ranged from 8.1-14.2 $\mu \mathrm{g} \mathrm{g}^{-1}$ sed. dw in the Sfax-Kerkennah channel (R102, R105-R107, R208, R209) to $173.9 \mu \mathrm{g} \mathrm{g}^{-1}$ sed. dw in the Sfax harbor (R201). High values were also recorded in the Sfax-Kerkennah channel (45.7 $\mu \mathrm{g} \mathrm{g}^{-1}$ sed. dw, R104) and the Kerkennah harbor (72.1 $\mathrm{\mu g} \mathrm{g}^{-1}$ sed. dw, R111) (Table 3;

Fig. 2c). These $R$ concentrations (8.1- $173.9 \mu \mathrm{g} \mathrm{g}^{-1} \mathrm{sed}$. $\left.\mathrm{dw}\right)$ were quite high compared to 
those reported in the surficial/surface sediments from other regions of the Mediterranean Sea (Table 4). Indeed, for the sediments from Abu Qir Bay (Egypt), Gulf of Lions, Gulf of Fossur-mer, Berre lagoon (France), Gulf of Trieste (Italy), Catalan coast (Spain), Cretan Sea (Greece) and Coastal Aegean Sea (Tukey), concentrations did not exceed $10 \mu \mathrm{g} \mathrm{g}^{-1}$ sed. dw (Lipiataou and Saliot, 1991b; Tolosa et al., 1996; Gogou et al., 2000; El Deeb et al., 2007; Mille et al., 2007; Gonul and Kucuksezgin, 2012; Kanzari et al., 2012; Bajt, 2014; Mandalakis et al., 2014) (Table 4). In the Gulf of Tunis, Khniss coast (Tunisia), Tangier coastal zone (Morocco), Rhône delta (France), Patroklos and Sitia areas (Greece) and Aliağa Bay (Turkey), maximal concentrations were comprised between 10 and $57 \mu \mathrm{g} \mathrm{g}^{-1}$ sed. $\mathrm{dw}$ (Lipiatou and Saliot, 1991b; Tsapakis et al., 2010; Mzoughi and Chouba, 2011; Bouzid et al., 2012; Neşer et al., 2012; Zrafi et al., 2013) (Table 4). In Sfax ponds (Tunisia) and Eastern harbour of Alexandria (Egypt), maximal concentrations were 128 and $143 \mu \mathrm{g} \mathrm{g}^{-1}$ sed. dw, respectively (Aboul-Kassim and Simoneit, 1995; Elloumi et al., 2008). In the Sfax coastline (Tunisia), close to our study area, Zaghden et al. (2007) found concentrations reaching up to $430 \mu \mathrm{g} \mathrm{g}^{-1}$ sed. dw (sediments collected in 2003). Finally, Amori et al. (2011) observed concentrations that were largely higher, i.e. $3,886 \mu \mathrm{g} \mathrm{g}^{-1}$ sed. dw., in Gabès, Kettana and AlZar coastline (Tunisia). Hence, this comparison underscores that $n$-alkane concentrations in the surficial/surface sediments of the Tunisian coasts, particularly of the Gulf of Gabès, were among the highest measured in the Mediterranean Basin (Table 4).

Total PAH concentration (sum of 17 PAHs) varied between $175-245 \mathrm{ng} \mathrm{g}^{-1}$ sed. $\mathrm{dw}$ in the Sfax-Kerkennah channel (R109, R209, R208) and 10,769 $\mathrm{ng} \mathrm{g}^{-1}$ sed. dw in the Sfax harbor (R201), with concentrations $>1,000 \mathrm{ng} \mathrm{g}^{-1}$ sed. $\mathrm{dw}$ recorded in the Sfax-Kerkennah channel (R104) and in the vicinity of Sfax (R204, R203, R202) and Kerkennah (R110, R111) harbors (Table 5; Fig. 2d). These total PAH concentrations (175-10,769 $\mathrm{ng} \mathrm{g}^{-1}$ sed. dw) mirror a moderate to very high pollution level according to the pollution level classification proposed 
by Baumard et al. (1998) (Table 5) and were situated in the mid-range of those reported in the surficial/surface sediments from other regions of the Mediterranean Sea (Table 6). Actually, for the sediments from Bizerte lagoon, Khniss coast (Tunisia), Al Hoceïma coastal area (Morocco), Bay of Banuyls-sur-mer (France), Chioggia and Ancona coastal zones (Italy), Cretan Sea (Greece), Candarli Gulf (Turkey) and Cilician Basin (Cyprus), concentrations did not exceed 1,000 $\mathrm{ng} \mathrm{g}^{-1}$ sed. dw (Magi et al., 2002; Pavoni et al., 2003; Trabelsi and Driss, 2005; Charles et al., 2012; Kucuksezgin et al., 2012, 2013; Zrafi et al., 2013; Barhoumi et al., 2014; Mandalakis et al., 2014) (Table 6). Also, in the Sfax, Luza, Sousse, Jarzouna-Bizerte coastal areas, Gulf of Tunis (Tunisia), Abu Qir Bay (Egypt), Rhône Delta, Port Vendres harbor (France), Gulf of Trieste (Italy) and coastal Aegean Sea (Turkey), maximal concentrations were comprised between 1,000 and $<10,000 \mathrm{ng} \mathrm{g}^{-1}$ sed. dw (Bouloubassi and Saliot, 1993; Baumard et al., 1998; Khairy et al., 2009; Zrafi-Nouira et al., 2010; Mzoughi and Chouba, 2011; Gonul and Kucuksezgin, 2012; Kessabi et al., 2013; Bajt, 2014; Zaghden et al., 2014) (Table 6). Nevertheless, in Egypt coastal areas, Lazaret Bay, Gulf of Fos-sur-mer (France), Taranto Gulf, Coastal Ligurian Sea, Venice Lagoon, Naples harbor (Italy), Santander Bay, Catalonia coast (Spain), Gulf of Corinth, North Evoikos and Saronikos Gulfs, Drapetsona-Keratsini coastal zone (Greece), Izmit and Aliağa Bays (Turkey), Rovinj coastal area and Rijeka Bay (Croatia), maximal concentrations were much higher than $10,000 \mathrm{ng} \mathrm{g}^{-1}$ sed. dw (La Rocca et al., 1996; Benlahcen et al., 1997; Eljarrat et al., 2001; Viguri et al., 2002; Bertolotto et al., 2003; Bihari et al., 2006; Tolun et al., 2006; Mille et al., 2007; Sprovieri et al., 2007; Annicchiarico et al., 2011; Alebic-Juretic, 2011; Barakat et al., 2011; Botsou and Hatzianestis, 2012; Neşer et al., 2012; Kapsimalis et al., 2014) (Table 6). It should be noticed that our total PAH concentrations were similar to those recorded by Zaghden et al. (2007) for the same area (113-10,720 $\mathrm{ng} \mathrm{g}^{-1}$ sed. dw) (sediments collected in 2003). 
Sediment quality guidelines (SQGs) are used to assess the contamination level of marine and estuarine sediments (Long et al. 1995; Barhoumi et al., 2014). Long et al. (1995) proposed two guideline values, an effects range low (ERL) and an effects range median (ERM) to determine the sediment quality. Our PAH concentrations were thus compared to these ERL and ERM values (Table 7). Total PAH concentrations in all stations were below ERL, except in R202 (close to Sfax harbor) and R201 (Sfax harbor) where they were comprised between ERL and ERM. At the level of individual compounds, concentrations in Nap, $\mathrm{BaA}$ and $\mathrm{BaP}$ were below ERL in all stations, while concentrations in Phe, Ant, Flt and Chr were below ERL or between ERL and ERM depending on the stations. Concentration in Pyr was > ERM in R201 (Table 7). Consequently, PAH concentrations in surficial sediments in this Sfax-Kerkennah channel area may be harmful for marine biota mainly in the Sfax harbor.

\subsection{Sediment geochemistry and relationships between hydrocarbons and}

\section{biogeochemical parameters}

Stations displaying high C, H, N, S, TOC, $R$ and PAH contents were the Sfax (R201) and Kerkennah (R111) harbors as well as station R104 (in the channel), and, in a lesser extent, station R110 (close to Kerkennah harbor; outside the channel). Except R110 (fine sand), these stations were characterized by very fine sand (Tables 3, 5; Fig. 2a, c, d), which may be linked to the relatively high PAH levels encountered. Indeed, PAHs are known to be mainly adsorbed onto very fine particles because of their higher specific surface area (Xia and Wang, 2008). TOC/N and $\delta^{13} \mathrm{C}$ values emphasized a mixed (marine and terrestrial) origin of organic matter (Tables 3; Fig. 2b), while the hydrocarbon levels suggested significant anthropogenic inputs in this sites. In the Sfax and Kerkennah harbors, anthropogenic inputs were rather evident with ship traffic and petroleum wastes. Nevertheless, specific 
anthropogenic sources were less obvious in station R104. The latter was located in a cuvette that might receive particular industrial wastewaters. In general, sediments with high organic carbon content contained high PAH concentrations (Barhoumi et al., 2014). However, station R107 (in the channel) presented a high TOC concentration and, in the meantime, low $R$ and PAH levels compared to those of stations R201, R111 and R104. R107 was also typified by medium sand and by a terrestrial fingerprint of the organic matter with regard to its TOC/N and $\delta^{13} \mathrm{C}$ values. An inverse pattern was observed in stations R202-R204 with high $R$ and PAH concentrations and a very low TOC content. TOC/N and $\delta^{13} \mathrm{C}$ showed a marine and terrestrial origin of organic matter (Tables 3, 5; Fig. 2a-d). These stations, located outside (R202) or at the channel border (R203-204), were very likely under the influence of anthropogenic (PAH) inputs from the Sfax harbor and city. All other stations of the channel (R105, R106, R205-R210) as well as stations R108 and R109 (outside the channel) were characterized by fine or medium sand and presented the lowest $R$ and PAH concentrations, a low TOC content, a high $\mathrm{CaCO}_{3}$ content and TOC/N and $\delta^{13} \mathrm{C}$ values revealing both marine and terrestrial organic matter (Tables 3, 5; Fig. 2a-d). These sites were thus much less impacted by anthropogenic inputs. This was due to their relative greater distance from the coast and their higher bathymetry as well as to the North-East South-West-oriented current crossing the channel, which transports the finest particles further southward.

As mentioned above, strong decoupling occurred between hydrocarbon and TOC contents depending on the stations, especially for R107. As seen from Fig. 2e, f, the R/TOC and PAH/TOC ratios were not constant: low ratios were observed inside the channel $(<8 \mathrm{mg}$ $\mathrm{g}^{-1}$ and $<60 \mu \mathrm{g} \mathrm{g}^{-1}$ sed. $\mathrm{dw}$, respectively), while high ratios were found in coastal stations outside the channel (> $10 \mathrm{mg} \mathrm{g}^{-1}$ and $>500 \mu \mathrm{g} \mathrm{g}^{-1}$ sed. $\mathrm{dw}$, respectively). When taken into account all stations $(\mathrm{n}=20)$, significant positive linear correlations appeared between total $R$ concentration and C, H, N, S and TOC contents $(r=0.49-0.93, \mathrm{p}<0.05, \mathrm{n}=20)$, and between 
total PAH concentration and $\mathrm{H}, \mathrm{N}$ and $\mathrm{S}$ contents $(\mathrm{r}=0.73-0.81, \mathrm{p}<0.05, \mathrm{n}=20)$. A significant correlation was also found between total $R$ and PAH concentrations $(\mathrm{r}=0.85, \mathrm{p}<$ $0.05, \mathrm{n}=20$ ) (Table 8). When removing station $\mathrm{R} 107$ from the dataset, for which the decoupling between hydrocarbons and TOC was very pronounced (this station appeared as outlier when plotting the data), correlations between $R$, PAHs and TOC clearly increased $(\mathrm{r}=$ 0.66-0.88, $\mathrm{p}<0.05, \mathrm{n}=19$ ) (Table 8). However, when station R201 (i.e. the station showing "extreme" hydrocarbon concentrations) was also excluded in addition to R107, the degree of correlation between parameters dropped: PAHs were not correlated anymore to TOC and $R$ (r $=-0.08-0.21, \mathrm{p}>0.05, \mathrm{n}=18)$, whereas the correlation between the two latter substantially decreased $(r=0.68, p<0.05, n=18)$ (Table 8). Finally, when eliminating R107 and all stations with total PAH concentration > $1000 \mathrm{ng} \mathrm{g}^{-1}$ sed. dw (i.e. R201, R104, R110, R111, R202-R204), the correlation between $R$ and TOC disappeared as well $(\mathrm{r}=-0.02, \mathrm{p}>0.05, \mathrm{n}=$

12) (Table 8). This correlation study shows that the significant correlations occurring between $R$, PAHs and TOC were almost merely due to the "extreme" station R201. Therefore, the distribution and concentrations of $R$, PAHs and TOC were decoupled in the surficial sediments of the Sfax-Kerkennah channel. $R$ and PAHs were very likely more influenced by specific inputs rather than by organic matter content. The absence of significant linear relationship between PAH and TOC concentrations or between $R$ and PAH concentrations in surficial/surface sediments were also reported for the Bizerte Lagoon (Tunisia), Marano and Grado Lagoons (Italy) and Egyptian coastal areas (El Nemr et al., 2013; Aquavita et al., 2014; Barhoumi et al., 2014). Moreover, Simpson et al. (1996) proposed that PAH and TOC concentrations in sediments are significantly correlated solely in greatly contaminated sites where total PAH concentrations $>2,000 \mathrm{ng} \mathrm{g}^{-1}$, which is in accordance with our results.

\subsection{Composition and sources of hydrocarbons}


The $\mathrm{UCM} / R$ ratio was $>3$ for stations R106, R111 (Kerkennah harbor), R201 (Sfax harbor), R202, R208-R210 (Sfax-Kerkennah channel) (Table 3), which reflects the presence of degraded petroleum products in these stations (Simoneit and Mazurek, 1982; Guigue et al., 2011; Parinos et al., 2013). $\mathrm{CPI}_{15-24}$ was $<1$ for all the stations, except for the Sfax harbor (R201) where it was close to 1 (Table 3). This shows the predominance of even carbon number in short chain $n$-alkanes. Indeed, $n-\mathrm{C}_{16}, n-\mathrm{C}_{18}$ and, in a lesser extent, $n$ - $\mathrm{C}_{20}$ were the dominant compounds over the whole range $n-\mathrm{C}_{15}-n-\mathrm{C}_{34}$ apart from the coastal stations $\mathrm{R} 101-$ R103, the Kerkennah harbor area (R110, R111) and the Sfax harbor (R201), in which $n-\mathrm{C}_{31}$ and $n$ - $\mathrm{C}_{33}$ were the major compounds. The predominance of even light $n$-alkanes $n$-C ${ }_{16}, n$ - $\mathrm{C}_{18}$ and $n-\mathrm{C}_{20}$ in sediments is not so common albeit it has been observed for instance in sediments from the Arabian Gulf (Grimalt et al., 1985), the Gulf of Fos-sur-mer (Mille et al., 2007) and the Taihu Lake, China (Yu et al., 2016). It has been suggested that these even light $n$-alkanes were issued from bacteria, but also fungi, and yeast species, and from petroleum-derived inputs (Mille et al., 2007; Harji et al. 2008; Yu et al., 2016). $\mathrm{CPI}_{25-34}$ displayed values > 3 for stations R101-R110 and R208 (Table 3). This underscored the presence of AHs from mixed petroleum and biogenic (terrestrial higher plant debris) sources, the latter having a higher contribution (Rieley et al., 1991; Harji et al., 2008). In contrast, for almost all the stations from the Kerkennah-Sfax city transect, $\mathrm{CPI}_{25-34}$ was $<3$ (Table 3), which emphasised an increase in the contribution of petroleum inputs (Mille et al., 2007; Guigue et al., 2011). TAR was $>1$ in most of stations, being comprised between 1.2 and 2.8, with high values of 6.6 and 10.4 detected in R102 and R103. TAR was $~ 1.0$ in stations R106 and R205 and $<1$ in R104, R107, R202 and R207 (Table 3). Hence, this ratio mirrored the higher contribution of terrestrial higher plants compared to aquatic material (algae, phyto- and zoo-plankton).

Ratios involving $\operatorname{Pr}$ and $\mathrm{Phy}\left(\mathrm{Pr} / \mathrm{Phy}, n-\mathrm{C}_{17} / \mathrm{Pr}\right.$ and $\left.n-\mathrm{C}_{18} / \mathrm{Phy}\right)$ have to be taken with extreme caution because these branched alkanes have multiple origins and are sensitive to 
diagenetic conditions and thermal maturity (Peters et al., 2005). They are both derived from the phytol side chain of chlorophyll $a$, either under reducing conditions (Phy) or oxidizing conditions (Pr). They are thus abundant in weathered crude oils. However, Pr can also originate from zooplankton, and Phy from Archaebacteria, such as methanogens (Volkman et al., 1992). It has been proposed that $\mathrm{Pr} / \mathrm{Phy}<1$ could be taken as an indicator of petroleum origin and/or highly reducing (anoxic, hypersaline) depositional environments. Pr/Phy > 3 may reflect the presence of biogenic AHs, while Pr/Phy between 1 and 3 may be the sign of oxidizing depositional environments (Volkman et al., 1992; ten Haven, 1996; Peters et al., 2005). Here, we found Pr/Phy < 1 for all the stations, except R110, R201, R208 and R209, which presented values comprised between 1.19 and 2.85 (Table 3). These Pr/Phy values (< 3) underlined the absence of biogenic AHs. Although no significant correlation was found between Pr/Phy ratio or Phy concentration and \% S (data not shown), we may assume that the relatively high sulphur content in these sediments (underscoring the occurrence of anoxic conditions) contributed to the relatively low Pr/Phy values observed, in addition to the petroleum signature. These results are in agreement with those from Zaghden et al. (2007) in the same area. The $n-\mathrm{C}_{18} / \mathrm{Phy}$ ratio was $>1$ for all the stations. Values comprised between 2 and 5 were observed for a majority of stations, whereas higher values (6-9) were found in stations R107, R205, R209, R210 (Table 3). Interestingly, the highest value was detected in R107 suggesting a very recent hydrocarbon input that could be related to the relatively high TOC concentration found in this station. In the Sfax harbor area, $n-\mathrm{C}_{18} / \mathrm{Phy}$ decreased $(\sim 1.7$ in R201 and R202) (Table 3), which reflected the presence of more degraded AHs. The $n$ $\mathrm{C}_{17} / \mathrm{Pr}$ ratio, which showed values around 1 for several stations from coastal areas and the Sfax-Kerkennah channel, did not follow the same trend than the $n-\mathrm{C}_{18} /$ Phy ratio (Table 3). Its interpretation seems thus more complicated. This analysis of AH ratios and indices suggests the presence of both petrogenic and biogenic materials, the petrogenic fingerprint being more 
accentuated in the harbor areas and in the Kerkennah-Sfax city transect compared to North of Sfax-Kerkennah transect.

Concerning PAHs, the most abundant compounds were $\sum \mathrm{MePyr}$ (in R101, R104, R110, R111, R207, R203, R201), ¿MePhe (in R102, R106, R107, R204) or Chr and/or $\sum M e C h r(i n$ R103, R105, R210, R205), which accounted on average for $20 \%$ of total PAHs (Table 5). Per (35\%), $\mathrm{BgP}(34 \%), \mathrm{BaP}(30 \%)$, Flt (17\%) and $\mathrm{BkF}(19 \%)$ dominated in R108, R109, R209, R208 and R202, respectively. Nap, $\sum$ MeNap, Ant and BaA were not detected, except in R103, R209, R204, R203 and/or R202 (Table 5). High proportions of alkylated Pyr and Phe in the Sfax sediments have already been pointed out by Zaghden et al. (2007; 2014). Hence, PAH molecular profiles illustrated the predominance of 4-ring compounds apart from stations R204 (dominance of 3 rings), R108, R209 (dominance of 5 rings) and R109 (dominance of 6 rings) (Fig. 3).

Fig. 4 presents the cross plot of $\sum$ LMW/ $/ \mathrm{HMW}$ versus Flt/Flt+Pyr ratios for the different samples, except stations R106, R209 and R210, for which Flt/Flt+Pyr could not be determined. Most of the stations (R101-R105, R107, R109-R111, R205, R201) displayed $\sum \mathrm{LMW} / \sum \mathrm{HMW}$ ratio $<1$ and Flt/Flt+Pyr ratio $<0.4$, which highlighted both petrogenic and pyrogenic sources of PAHs. In station R204, the inverse pattern ( $\sum$ LMW/ $/$ HMW $>1$ and Flt/Flt+Pyr < 0.4), suggested this mixed source as well. On the contrary, stations R108, R202, R203, R207 and R208 presented $\sum$ LMW/ 2 HMW ratio $<1$ and Flt/Flt+Pyr ratio > 0.4, putting forward the dominance of the pyrogenic source (Soclo et al., 2000; Yunker et al., 2002; Li et al., 2006; Zhang et al., 2008). R108, R202, R203 and R207 had Flt/Flt+Pyr ratio < 0.5, which might be attributed to fuel combustion. R208, with Flt/Flt+Pyr ratio of 0.74, was distinguished by a contribution of grass, coal, and/or wood combustion (De La Torre-Roche et al., 2009; Fig. 4; Table 2). On the other side, $\sum \mathrm{MePhe} / \mathrm{Phe}$ ratio was $>2$ with the exception of stations R109 and R210, which implied the dominance of the petrogenic source (Prahl and 
Carpenter 1983; Garrigues et al., 1995). In the same way, $\sum$ MePyr/Pyr was > 1 apart from R107, R205 and R203, underscoring the petrogenic fingerprint (Zaghden et al., 2007; 2014). At last, $\mathrm{BaP} / \mathrm{BgP}$ was $>$ 0.6, except for R103, R109 and R201. This could reflect traffic emissions (Katsoyiannis et al., 2007; Table 2). Consequently, from these different indices and ratios, it appears that the Sfax-Kerkennah channel area was characterized by various petrogenic and pyrogenic sources of PAHs, with no clear trend highlighted between coastal stations (outside the channel) and stations inside the channel.

\section{Conclusion}

This study investigated the origin and distribution of hydrocarbons (AHs and PAHs) and organic matter in the surficial sediments of the Sfax-Kerkennah channel. Sediments, mainly composed of sand, displayed a grain size distribution in relation with the geomorphology, bathymetry and hydrodynamic properties of the Sfax-Kerkennah channel. Fine and very fine sands were generally found outside the channel (coastal stations and harbors), whereas medium sand was observed within the channel (deepest stations). Compared to other regions of the Mediterranean Sea, we recorded high TOC concentrations (> 11\%), quite high $R$ (up to $174 \mu \mathrm{g} \mathrm{g}^{-1}$ sed. $\mathrm{dw}$ ) and PAH concentrations (> 10,000 $\mathrm{ng} \mathrm{g}^{-1}$ sed. dw). According to Baumard et al. (1998), PAH pollution was moderate to very high in the Sfax-Kerkennah channel. Moreover, with regard to sediment quality guidelines (Long et al., 1995), the pyrene concentration in the Sfax harbor sediment may be detrimental for marine ecosystems. In the Sfax and Kerkennah harbors as well as in stations R104 and R110, we found high contents in C, H, N, S, TOC, $R$ and PAHs. Except for station R110, these high contents were associated with very fine sand. In contrast, most of the stations located within the channel were characterized by fine or medium sand and by low TOC, $R$ and PAH concentrations. 
Nevertheless, by examining in details the degree of correlation between parameters, we put forward that $R$, PAHs and TOC were actually decoupled for most of the stations. This suggested that hydrocarbons were very likely more influenced by specific inputs rather than by organic matter content in the surficial sediments of the Sfax-Kerkennah channel. TOC/N and $\delta^{13} \mathrm{C}$ values revealed a mixed origin of organic matter with both autochthonous marine and terrestrial sources. Index and ratio diagnostic emphasized the dominance of petrogenic origin of $n$-alkanes (relatively to biogenic origin) and the presence of both petrogenic and pyrogenic PAHs. AH ratios revealed the presence of both biogenic and petrogenic materials, the petrogenic fingerprint being more important and more degraded in the harbor areas and in the Kerkennah-Sfax city transect. However, PAH diagnostic did not reveal any clear relationship between the geographical repartition of stations and the molecular composition/origin of hydrocarbons. This work underscores the complex distribution patterns and the multiple sources (marine, terrestrial, anthropogenic) of organic matter and hydrocarbons in the Gulf of Gabès. Also, further investigations should consider the molecular composition of hydrocarbons in the water column (particulate and dissolved phases) for a global view of organic pollutant dynamics in coastal waters of the Gulf of Gabès.

Acknowledgements. We acknowledge the service central d'analyses du CNRS (Vernaison, France). We are grateful to Pr. J.-L. Reyss (LSCE, UMR CEA-CNRS 1572, France) for providing access to $\mathrm{CHN}$ and isotope ratio equipment. We warmly thank A. Lorre for her help and assistance for $\mathrm{OC}$ and $\delta^{13} \mathrm{C}$ analyses. One anonymous Reviewer is acknowledged for his relevant comments and corrections. This work was conducted in part in the framework of the IRD French-Tunisian International Joint Laboratory "LMI COSYSMed". 


\section{References}

Aboul-Kassim, T.A.T., Simoneit, B.R.T., 1995. Petroleum hydrocarbon fingerprinting and sediment transport assessed by molecular biomarker and multivariate statistical analyses in the Eastern Harbour of Alexandria, Egypt. Mar. Pollut. Bull. 30, 63-73.

Acquavita, A., Falomo, J., Predonzani, S., Tamberlich, F., Bettoso, N., Mattassi, G., 2014. The PAH level, distribution and composition in surface sediments from a Mediterranean Lagoon: The Marano and Grado Lagoon (Northern Adriatic Sea, Italy). Mar. Pollut. Bull. $81,234-241$.

Alebic-Juretic, A., 2011. Polycyclic aromatic hydrocarbons in marine sediments from the Rijeka Bay area, Northern Adriatic, Croatia, 1998-2006. Mar. Pollut. Bull. 62, 863-869. Aloulou, F., Elleuch, B., Kallel, M., 2012. Benthic foraminiferal assemblages as pollution proxies in the northern coast of Gabes Gulf, Tunisia. Environ. Monit. Assess. 184, 777795.

Aloulou, F., Kallel, M., Dammak, M., Elleuch, B., Saliot, A., 2010. Even-numbered nalkanes/n-alkenes predominance in surface sediments of Gabes Gulf in Tunisia. Environ. Earth Sci. 61, 1-10.

Amorri, J., Geffroy-Rodier, C., Boufahja, F., Mahmoudi, E., Aïssa, P., Ksibi, M., Amblès, A., 2011. Organic matter compounds as source indicators and tracers for marine pollution in a western Mediterranean coastal zone. Environ. Sci. Pollut. Res. Int. 18, 1606-1616.

Annicchiarico, C., Buonocore, M., Cardellicchio, N., Di Leo, A., Giandomenico, S., Spada, L., 2011. PCBs, PAHs and metal contamination and quality index in marine sediments of the Taranto Gulf. Chem. Ecol. 27, 21-32.

Asia, L., Mazouz, S., Guiliano, M., Doumenq, P., Mille, G., 2009. Occurrence and distribution of hydrocarbons in surface sediments from Marseille Bay (France). Mar. Pollut. Bull. 58, 443-451. 
Bajt, O., 2014. Aliphatic and Polycyclic Aromatic Hydrocarbons in Gulf of Trieste Sediments (Northern Adriatic): Potential Impacts of Maritime Traffic. Bull. Environ. Contam. Toxicol. 93, 299-305.

Barakat, A.O., Mostafa, A., Wade, T.L., Sweet, S.T., El Sayed, N.B., 2011. Distribution and characteristics of PAHs in sediments from the Mediterranean coastal environment of Egypt. Mar. Pollut. Bull. 62, 1969-1978.

Barhoumi, B., LeMenach, K., Devier, M.H., Ben Ameur, W., Etcheber, H., Budzinski, H., Cachot, J., Driss, M.R., 2014. Polycyclic aromatic hydrocarbons (PAHs) in surface sediments from the Bizerte Lagoon, Tunisia: levels, sources, and toxicological significance. Environ. Monit. Assess. 186, 2653-2669.

Barth, A., Alvera Azcarate, A., Troupin, C., Ouberdous, M., Beckers, J.-M., 2010. A web interface for griding arbitrarily distributed in situ data based on Data-Interpolating Variational Analysis (DIVA). Adv. Geosci. 28, 29-37.

Baumard, P., Budzinski, H., Michon, Q., Garrigues, P., Burgeot, T., Bellocq, J., 1998. Origin and bioavailability of PAHs in the Mediterranean Sea from mussel and sediment records. Estuar. Coast. Shelf Sci. 47, 77-90.

Ben Ameur, W., Trabelsi, S., Driss, M.R., 2010. Polycyclic aromatic hydrocarbons in superficial sediments from Ghar El Melh Lagoon, Tunisia. Bull. Environ. Contam. Toxicol. 85, 184-189.

Ben Mustapha, K., Hattour, A., Mhetli, M., El Abed, A., Tritar. B., 1999. Bionomie des étages infra et circalittoral du golfe de Gabès. Bull. Inst. Natl. Sci. Tech. Mer (Tunisie) 26, $5-48$.

Benlahcen, K.T., Chaoui, A., Budzinski, H., Bellocq, J., Garrigues, P.H., 1997. Distribution and sources of polycyclic aromatic hydrocarbons in some Mediterranean coastal sediments. Mar. Pollut. Bull. 34, 298-316. 
Ben Othman, S., 1973. Le sud tunisien (golfe de Gabès) : Hydrologie, sédimentologie, flore et faune. $\mathrm{PhD}$ thesis. Université de Tunis, $166 \mathrm{pp}$.

Berner, R.A., 1989. Biogeochemical cycles of carbon and sulfur and their effect on atmospheric oxygen over Phanerozoic time. Paleogeogr. Paleoclimatol. Paleoecol. 75, 97122.

Bertolotto, R.M., Ghioni, F., Frignani, M., Alvarado-Aguilar, D., Bellucci, L.G., Cuneo, C., Picca, M.R., Gollo, E., 2003. Polycyclic aromatic hydrocarbons in surficial coastal sediments of the Ligurian Sea. Mar. Pollut. Bull. 46, 907-913.

Bihari, N., Fafandel, M., Hamer, B., Kralj-Bilen, B., 2006. PAH content, toxicity and genotoxicity of coastal marine sediments from the Rovinj area, Northern Adriatic, Croatia. Sci. Tot. Environ. 366, 602-611.

Blott, S.J., Pye, K., 2001. GRADISTAT: a grain size distribution and statistics package for the analysis of unconsolidated sediments. Earth Surf. Process. Landf. 26, 1237-1248.

Blumer, M., Mullin, M.M., Thomas, D.W., 1963. Pristane in zooplankton. Science 140, 974.

Botsou, F., Hatzianestis, I., 2012. Polycyclic aromatic hydrocarbons (PAHs) in marine sediments of the Hellenic coastal zone, eastern Mediterranean: levels, sources and toxicological significance. J. Soils Sediments 12, 265-277.

Bouaziz, S., Jedoui, Y., Barrier, E., Angelier, J., 2003. Néotectonique affectant les dépôts marins tyrrhéniens du littoral sud-est tunisien: implications pour les variations du niveau marin. C. R. Géosci. 335, 247-254.

Bouloubassi, I., Saliot, A., 1993. Investigation of anthropogenic and natural organic inputs in estuarine sediments using hydrocarbon markers (NAH, LAB, PAH). Oceanol. Act. 16, $145-161$. 
Bouloubassi, I., Méjanelle, L., Pete, R., Fillaux, J., Lorre, A., Point, V., 2006. PAH transport by sinking particles in the open Mediterranean Sea: a 1 year sediment trap study. Mar. Pollut. Bull. 52, 560-571.

Bourbonniere, R.A., Meyers, P.A., 1996. Sedimentary geolipid records of historical changes in the watersheds and productivities of Lakes Ontario and Erie. Limnol. Oceanogr. 41, $352-359$.

Bouzid, S., Raissouni, A., Khannous, S., El Arrim, A., Bouloubassi, I., Saliot, A., Er-Raioui, H., 2012. Distribution and origin of aliphatic hydrocarbons in surface sediments of strategical areas of the western moroccan mediterranean sea. Open Environ. Pollut. Toxicol. J. 3, 13-22.

Brändli, R.C., Bucheli, T.D., Ammann, S., Desaules, A., Keller, A., Blum, F., Stahel, W.A., 2008. Critical evaluation of PAH source apportionment tools using data from the Swiss soil monitoring network. J. Environ. Monit. 10, 1278-1286.

Budzinski, H., Jones, I., Bellocq, J., Pierard, C., Garrigues, P., 1997. Evaluation of sediment contamination by polycyclic aromatic hydrocarbons in the Gironde estuary. Mar. Chem. $58,85-97$.

Charles, F., Nozais, C., Pruski, A.M., Bourgeois, S., Méjanelle, L., Vétion, G., Rivière, B., Coston-Guarini, J., 2012. Ecodynamics of PAHs at a peri-urban site of the French Mediterranean Sea. Environ. Pollut. 171, 256-264.

Chen, J., Henderson, G., Grimm, C.C., Lloyd, S.W., Laine, R.A., 1998. Termites fumigate their nests with naphthalene. Nature 392, 558.

Cincinelli, A., Martellini, T., Bittoni, L., Russo, A., Gambaro, A., Lepri, L., 2008. Natural and anthropogenic hydrocarbons in the water column of the Ross Sea (Antarctica). J. Mar. Syst. 73, 208-220.

Clark, R.B., 1997. Marine Pollution. fourth ed. Claredon Press, Oxford, p. 270. 
Commendatore, M.G., Esteves, J.L., 2004. Natural and anthropogenic hydrocarbons in sediments from the Chubut River (Patagonia, Argentina). Mar. Pollut. Bull. 48, 910-918.

Cripps, G.C., 1989. Problems in the identification of anthropogenic hydrocarbons against natural background levels in the Antartic. Antarctic Sci. 14, 307-312.

Dachs, J., Méjanelle, L., 2010. Organic Pollutants in Coastal Waters, Sediments, and Biota: A Relevant Driver for Ecosystems During the Anthropocene? Estuar. Coasts 33, 1-14.

De La Torre-Roche, R.J., Lee, W.-Y., Campos-Díaz, S.I., 2009. Soil-borne polycyclic aromatic hydrocarbons in El Paso, Texas: analysis of a potential problem in the United States/Mexico border region. J. Hazard. Mater. 163, 946-958.

DGPA, 2010. Direction Générale de Pêche et de l'Aquaculture. Annuaire des statistiques de pêche de Tunisie. D.G.P.A., 144 pp.

D’Ortenzio, F., d'Alcalà, M.R., 2009. On the trophic regimes of the Mediterranean Sea: A satellite analysis. Biogeosciences 6, 139-148.

Emerson, S., Hedges, J.I., 1988. Processes controlling the organic carbon content of open ocean sediments. Paleoceanography 3, 621-634.

Eglinton, G., Hamilton, R.J., 1967. Leaf epicuticular waxes. Science 156, 1322-1335.

Eljarrat, E., Caixach, J., Rivera, J., De Torres, M., Ginebreda, A., 2001. Toxic potency assessment of non- and mono-ortho PCBs, PCDDs, PCDFs, and PAHs in northwest Mediterranean sediments (Catalonia Spain). Environ. Sci. Technol. 35, 3589-3594.

Elloumi, J., Guermazi, W., Ayadi, H., Bouaïn, A., Aleya, L., 2008. Detection of Water and Sediments Pollution of An Arid Saltern (Sfax, Tunisia) by Coupling the Distribution of Microorganisms With Hydrocarbons. Water Air Soil Pollut. 187, 157-171.

El Deeb, K.Z., Said, T.O., El Naggar, M.H., Shreadah, M.A., 2007. Distribution and Sources of Aliphatic and Polycyclic Aromatic Hydrocarbons in Surface Sediments, Fish and 
Bivalves of Abu Qir Bay (Egyptian Mediterranean Sea). Bull. Environ. Contam. Toxicol. $78,373-379$.

El Nemr, A., Said, T.O., Khaled, A., El Sikaily, A., Abd-Allah, A.M.A., 2007. The distribution and sources of polycyclic aromatic hydrocarbons in surface sediments along the Egyptian Mediterranean coast. Environ. Monit. Assess. 124, 343-359.

El Nemr, A., El-Sadaawy, M.M., Khaled, A., Draz, SO., 2013. Aliphatic and polycyclic aromatic hydrocarbons in the surface sediments of the Mediterranean: assessment and source recognition of petroleum hydrocarbons. Environ. Monit. Assess. 185, 4571-4589.

Folk, R.L., Ward, W.C., 1957. Brazos River bar: a study in the significance of grain size parameters. J. Sedimentary Petrol. 27, 3-26.

Garrigues, P., Budzinski, H., Manitz, M.P., Wise, S.A., 1995. Pyrolytic and petrogenic inputs in recent sediments: a definitive signature through phenanthrene and chysene compound distribution. Polycyclic Aromat. Compd. 7, 275-284.

Ghannem, N., Azri, C., Serbaji, M.M., Yaich C., 2011. Spatial Distribution of Heavy Metals in the Coastal Zone of “Sfax-Kerkennah”' Plateau, Tunisia. Environ. Progr. Sustain. Ener. $30,21-233$.

Gogou, A., Bouloubassi, I., Stephanou, E.G., 2000. Marine organic geochemistry of the Eastern Mediterranean: 1. Aliphatic and polyaromatic hydrocarbons in Cretan Sea surficial sediments. Mar. Chem. 68, 265-282.

Gonul, L.T., Kucuksezgin, F., 2012. Aliphatic and polycyclic aromatic hydrocarbons in the surface sediments from the Eastern Aegean: assessment and source recognition of petroleum hydrocarbons. Environ. Sci. Pollut. Res. 19, 31-41.

Grimalt, J., Albaiges, J., Al Saad, H.T., Douabul, A.A.Z., 1985. n-Alkane distributions in surface sediments from the Arabian Gulf. Naturwissenschaften 72, 35-37. 
Guerra, R., 2012. Polycyclic Aromatic Hydrocarbons, Polychlorinated Biphenyls and Trace Metals in Sediments from a Coastal Lagoon (Northern Adriatic, Italy). Water Air Soil Pollut. 223, 85-98.

Guigue, C., Tedetti, M., Giorgi, S., Goutx, M., 2011. Occurrence and distribution of hydrocarbons in the surface microlayer and subsurface water from the urban coastal marine area off Marseilles, Northwestern Mediterranean Sea. Mar. Pollut. Bull. 62, 27412752.

Harji, R.R., Yvenat, A., Bhosle, N.B., 2008. Sources of hydrocarbons in sediments of the Mandovi estuary and the Marmugoa harbour, west coast of India. Environ. Int. 34, 959965.

Illou, S., 1999. Impact des rejets telluriques d'origines domestiques et industrielles sur les environnements côtiers : cas du littoral nord de la ville de Sfax (Tunisie). Ph.D. thesis, Faculté des Sciences de Tunis.

Institut National de la Météorologie de Tunisie (INM), 2008. Données climatiques et statistiques annuelles des vents. Rapports Annuels (1981-2004), 118pp.

Jedoui, Y., 1980. Etude hydrologique et sédimentologique d'une lagune en domaine méditerranéen: Le bahiret el Boughrara (Tunisie). $\mathrm{PhD}$ thesis. Université de Bordeaux I, $190 \mathrm{pp}$.

Kanzari, F., Syakti, A.D., Asia, L., Malleret, L., Mille, G., Jamoussi, B., Abderrabba, M., Doumenq, P., 2012. Aliphatic hydrocarbons, polycyclic aromatic hydrocarbons, polychlorinated biphenyls, organochlorine, and organophosphorous pesticides in surface sediments from the Arc river and the Berre lagoon, France. Environ. Sci. Pollut. Res. 19, $559-576$.

Kapsimalis, V., Panagiotopoulos, I.P., Talagani, P., Hatzianestis, I., Kaberi, H., Rousakis, G., Kanellopoulos, T.D., Hatiris, G.A., 2014. Organic contamination of surface sediments in 
the metropolitan coastal zone of Athens, Greece: Sources, degree, and ecological risk. Mar. Pollut. Bull. 80, 312-324.

Katlane, R., Bergès, J.-C., Beltrando, G., Zargouni, F., 2014. Recent dynamics of submerged shoals and channels aroud the Kerkennah archipelago (Tunisia) from LANDSAT TM and MODIS. Proceedings for the 2nd Inter. Conf. Water resources and wetlands, 11-13 Sept, Tulcea (Romania), p. 361-365.

Katsoyiannis, A., Breivik, K., 2014. Model-based evaluation of the use of polycyclic aromatic hydrocarbons molecular diagnostic ratios as a source identification tool. Environ. Pollut. $184,488-494$.

Katsoyiannis, A., Terzi, E., Cai, Q.-Y., 2007. On the use of PAH molecular diagnostic ratios in sewage sludge for the understanding of the PAH sources. Is this use appropriate? Chemosphere 69, 1337-1339.

Ke, L., Wong, Y.S., Tam, N.F.Y., 2004. Determination of polycyclic aromatic hydrocarbons in mangrove sediments: Comparison of two internal standard surrogate methods and quality-control procedures. Int. J. Environ. An. Ch. 84, 661-675.

Kennish, M.J., 1992. Poly-nuclear aromatic hydrocarbons. Ecology of estuaries: anthropogenic effects. Boca Raton: CRC Press, p. 133-181.

Kessabi, K., Annabi, A, Hassine, A.I., Bazin, I., Mnif, W., Said, K., Messaoudi, I., 2013. Possible chemical causes of skeletal deformities in natural populations of Aphanius fasciatus collected from the Tunisian coast. Chemosphere 90, 2683-2689.

Khairy, M.A., Kolb, M., Mostafa, A.R., EL-Fiky, A., Bahadir, M., 2009. Risk assessment of polycyclic aromatic hydrocarbons in a Mediterranean semi-enclosed basin affected by human activities (Abu Qir Bay, Egypt). J. Hazard Mater. 170, 389-397. 
Kucuksezgin, F., Pazi, I., Gonul, L.T., 2012. Marine organic pollutants of the Eastern Aegean: Aliphatic and polycyclic aromatic hydrocarbons in Candarli Gulf surficial sediments. Mar. Pollut. Bull. 64, 2569-2575.

Kucuksezgin, F., Pazi, I., Gonul, L.T., Duman, M., 2013. Distribution and sources of polycyclic aromatic hydrocarbons in Cilician Basin shelf sediments (NE Mediterranean). Mar. Pollut. Bull. 71, 330-335.

La Rocca, C., Conti, L., Crebelli, R., Crochi, B., Iacovella, N., Rodriguez, F., TurrioBaldassarri, L., Di Domenico, A., 1996. PAHs content and mutagenicity of marine sediments from the Venice lagoon. Ecotoxicol. Environ. Safety 33, 236-245.

Leventhal, J.S., 1983. An interpretation of carbon and sulfur relationships in Black Sea sediments as indicators of environments of deposition. Geochim. Acta. 47, 133-137.

Li, G., Xia, X., Yang, Z., Wang, R., Voulvoulis, N., 2006. Distribution and sources of polycyclic aromatic hydrocarbons in the middle and lower reaches of the Yellow River, China. Environ. Pollut. 144, 985-993.

Lipiatou, E., Saliot, A., 1991a. Fluxes and transport of anthropogenic and natural polycyclic aromatic-hydrocarbons in the western Mediterranean Sea. Mar. Chem. 32, 51-71.

Lipiatou, E., Saliot A., 1991b. Hydrocarbon contamination of the Rhone delta and western Mediterranean Sea. Mar. Pollut. Bull. 22, 297-304.

Lipiatou, E., Tolosa, I., Simo, R., Bouloubassi, I., Dachs, J., Marti, S., Sicre, M.A., Bayona, J.M., Grimalt, J.O., Saliot, A., Albaigés, J., 1997. Mass budget and dynamics of polycyclic aromatic hydrocarbons in the Mediterranean Sea. Deep Sea Res. Part 2 Top. Stud. Oceanogr. 44, 881-905.

Liu, Y., Ling, C.N., Zhao, J.F., Huang, Q.H., Zhu, Z.L., Gao, H.W., 2008. Distribution and sources of polycyclic aromatic hydrocarbons in surface sediments of rivers and an estuary in Shanghai, China. Environ. Pollut. 154, 298-305. 
Long, E.R., Macdonald, D.D., Smith, S.L., Calder, F.D., 1995. Incidence of adverse biological effects with ranges of chemical concentrations in marine and estuarine sediments. Environ. Manage. 19, 81-97.

Louati, A., 2003. Etude de la contamination par hydrocarbures des sédiments de la région de Sfax (Tunisie). Phd Thesis. Université de Sfax et de Université Pierre et Marie Curie. Paris, $139 \mathrm{pp}$.

Louati, A., Elleuch, B., Kallel, M., Oudot, J., Saliot, A., Dagaut, J., 2001. Hydrocarbon contamination of coastal sediments from the Sfax area (Tunisia), Mediterranean Sea. Mar. Pollut. Bull. 42, 445-452.

Louiz, I., Kinani, S., Gouze, M.E., Ben-Attia, M., Menif, D., Bouchonnet, S., Porcher, J.M., Ben-Hassine, O.K., Aït-Aïssa, S., 2008. Monitoring of dioxin-like, estrogenic and antiandrogenic activities in sediments of the Bizerta lagoon (Tunisia) by means of in vitro cell-based bioassays: contribution of low concentrations of polynuclear aromatic hydrocarbons (PAHs). Sci. Tot. Environ. 402, 318-329.

Magi, E., Bianco, R., Ianni, C., Di Carro, M., 2002. Distribution of polycyclic aromatic hydrocarbons in the sediments of the Adriatic Sea. Environ. Pollut. 119, 91-98.

Mandalakis, M., Polymenakou, P.N., Tselepides, A., Lampadariou, N., 2014. Distribution of aliphatic hydrocarbons, polycyclic aromatic hydrocarbons and organochlorinated pollutants in deep-sea sediments of the southern Cretan margin, eastern Mediterranean Sea: A baseline assessment. Chemosphere 106, 28-35.

Martínez-Lladó, X., Gibert, O., Martí, V., Díez, S., Romo, J., Bayona, J.M., De Pablo, J., 2007. Distribution of polycyclic aromatic hydrocarbons (PAHs) and tributyltin (TBT) in Barcelona harbour sediments and their impact on benthic communities. Environ. Pollut. $149,104-113$. 
Mazurek, M.A., Simoneit, B.R.T., 1984. Characterization of biogenic and petroleum-derived organic matter in aerosols over remote rural and urban areas. In: L.H. Keith (Ed.). Identification and Analysis of Organic Pollutants in Air. Ann Arbor Science/Butterworth. Boston. pp. 353-370.

Meyers, P.A., 1994. Preservation of elemental and isotopic source identification of sedimentary organic matter. Chem. Geol. 144, 289-302.

Mille, G., Asia, L., Guiliano, M., Malleret, L., Doumenq, P., 2007. Hydrocarbons in coastal sediments from the Mediterranean sea (Gulf of Fos area, France). Mar. Pollut. Bull. 54, $566-575$

Monoley, C.L., Field, J.G., 1991. Modelling carbon and nitrogen flows in a microbial plankton community, In: PC. Reid et al. (Ed.), Protozoa and their role in marine processes, Springer, 443-474.

Muller, P.J., 1977. C/N ratios in Pacific deep-sea sediments: effects of inorganic ammonium and organic nitrogen compounds sorbed by clays. Geochim. Cosmochim. Acta 41, 765776.

Muller, P.J., Stress, E., 1979. Productivity, sedimentation rate and sedimentary carbon content in the oceans, 1- Organic carbon preservation. Deep Sea Res. 26A, 1347-1362.

Mzoughi, N., Chouba, L., 2011. Distribution and partitioning of aliphatic hydrocarbons and polycyclic aromatic hydrocarbons between water, suspended particulate matter, and sediment in harbours of the West coastal of the Gulf of Tunis (Tunisia). J. Environ. Monit. 13, 689-698.

Neff, J.M., 1979. Polycyclic aromatic hydrocarbons in the aquatic environment sources, fates and biological effects. Applied Science Publishers, LTD, London, p. 262. 
Neşer, G., Kontas, A., Unsalan, D., Altay, O., Darılmaz, E., Uluturhan, E., Küçüksezgin, F., Tekoğul, N., Yercan, F., 2012. Polycyclic aromatic and aliphatic hydrocarbons pollution at the coast of Aliağa (Turkey) ship recycling zone. Mar. Pollut. Bull. 64, 1055-1059.

Notar, M., Leskovšek, H., Faganeli, J., 2001. Composition, distribution and sources of polycyclic aromatic hydrocarbons in sediments of the Gulf of Trieste, Northern Adriatic Sea. Mar. Pollut. Bull. 42, 36-44.

Papadopoulou, D., Samara, C., 2002. Polycyclic aromatic hydrocarbon contamination and Lumistox (R) solvent extract toxicity of marine sediments in the North Aegean Sea, Greece. Environ. Toxicol. 17, 556-566.

Parinos, C., Gogou, A., Bouloubassi, I., Pedrosa-Pàmies, R., Hatzianestis, I., Sànchez-Vidal, A., Rousakis, G., Velaoras, D., Krokos, G., Lykousis, V., 2013. Occurrence, sources and transport pathways of natural and anthropogenic hydrocarbons in deep-sea sediments of the eastern Mediterranean Sea. Biogeosciences 10, 6069-6089.

Pavoni, B., Mecozzi, M., Berto, D., Ausili, A., Romano, E., Amici, M., Zharova, N., Amato, E., 2003. Environmental pollutants and organic carbon content in sediments from an area of the Moroccan Mediterranean Coast. Toxicol. Environ. Chem. 84, 53-67.

Peters, K.E., Watters, C.C., Moldowen, J.W., 2005. The Biomarker Guide, 2nd edn. Cambridge University Press, Cambridge UK.

Prahl, F.G., Carpenter, R., 1983. Polycyclic aromatic hydrocarbon (PAH)-phase associations in Washington coastal sediments. Geochim. Cosmochim. Acta 47, 1013-1023.

Readman, J.W., Fillmann, G., Tolosa, I., Bartocci, J., Villeneuve, J.-P., Catinni, C., Mee, L.D., 2002. Petroleum and PAH contamination of the Black Sea. Mar. Pollut. Bull. 44, 48-62. 
Rieley, G., Collier, R.J., Jones, D.M., Eglinton, G., 1991. The biogeochemistry of Ellesmere Lake, UK-I: source correlation of leaf wax inputs to the sedimentary lipid record. Org. Geochem. 17, 901-912.

Roose, P., Brinkman, U.A.Th., 2005. Monitoring organic microcontaminants in the marine environment: principles, programmes and progress. Trends Anal. Chem. 24, 897-926.

Sadouni-Barbedette, N., 2002. Contribution à l'étude de la biogéochimie de la mer Noire nord-ouest: approche par les biomarqueurs. Thèse de l'Université Pierre et Marie Curie, Paris, p. 235.

Sammari, C., Koutitonsky, V.G, Moussa, M., 2006. Sea level variability and tidal resonance in the Gulf of Gabes, Tunisia. Continental Shelf Res. 26, 338-350.

Serbaji, M.N., 2000. Utilisation d'un S.I.G. multi-sources pour la compréhension et la gestion intégrée de l'écosystème côtier de la région de Sfax (Tunisie). Ph.D. Thesis, University of Tunis II, p. 227.

Simoneit, B.R.T., Mazurek, M.A., 1982. Organic matter of the troposphere-II.* Natural background of biogenic lipid matter in aerosols over the rural western United States. Atmos. Environ. 16, 2139-2159.

Simpson, C.D., Mosi, A.A., Cullen, W.R., Reimer, K.J., 1996. Composition and distribution of polycyclic aromatic hydrocarbon contamination in surficial marine sediments from Kitimat Harbor, Canada. Sci. Total Environ. 181, 265-278.

Soclo, H.H., Garrigues, P.H., Ewald, M., 2000. Origin of polycyclic aromatic hydrocarbons (PAHs) in coastal marine sediments: case studies in Cotonou (Benin) and Aquitaine (France) areas. Mar. Pollut. Bull. 40, 387-396.

Sporstol, S., Gjos, N., Lichtenthaler, R.G., Gustaren, K.O., Urdal, K., Oreld, F., Skel, J., 1983. Source identification of aromatic hydrocarbons in sediments using GCrMS. Environ. Sci. Technol. 17, 282-286. 
Sprovieri, M., Feo, M.L., Prevedello, L., Manta, D.S., Sammartino, S., Tamburrino, S., Marsella, E., 2007. Heavy metals, polycyclic aromatic hydrocarbons and polychlorinated biphenyls in surface sediments of the Naples harbor (southern Italy). Chemosphere 67, 998-1009.

ten Haven, H.L., 1996. Applications and limitations of Mango's light hydrocarbon parameters in petroleum correlation studies. Org. Geochem. 24, 957-976.

The MerMex Group, 2011. Marine ecosystems responses to climatic and anthropogenic forcings in the Mediterranean. Prog. Oceanogr. 91, 97-166.

Tobiszewski, M., Namieśnik, J., 2012. PAH diagnostic ratios for the identification of pollution emission sources. Environ. Pollut. 162, 110-119.

Tolosa, M., Bayona, O.M., Albaigés, O., 1996. Aliphatic and polycyclic aromatic hydrocarbons and sulfur/oxygen derivatives in Northwestern Mediterranean sediments: Spatial and temporalvariability, fluxes, and budgets. Environ. Sci. Technol. 30, 24952503.

Tolun, L.,Martens,D.,Okay,O.S.,Schramm, K.W.,2006.Polycyclic aromatic hydrocarbon contamination in coastal sediments of the Izmit Bay (Marmara Sea): case studies before and after the Izmit Earthquake. Environ. Int. 32, 758-765.

Trabelsi, S., Driss, M.R., 2005. Polycyclic aromatic hydrocarbons in superficial coastal sediments from Bizerte Lagoon, Tunisia. Mar. Pollut. Bull. 50, 344-359.

Troupin, C., Barth, A., Sirjacobs, D., Ouberdous, M., Brankart, J.-M., Brasseur, P., Rixen, M., Alvera Azcarate, A., Belounis, M., Capet, A., Lenartz, F., Toussaint, M.-E., \& Beckers, J.M., 2012. Generation of analysis and consistent error fields using the Data Interpolating Variational Analysis (Diva). Ocean Model. 52-53, 90-101. 
Tsapakis, M., Dakanali, E., Stephanou, E.G., Karakassis, I., 2010. PAHs and n-alkanes in Mediterranean coastal marine sediments: aquaculture as a significant point source. $\mathbf{J}$ Environ Monit. 12, 958-963.

UNEP/IOC/IAEA. 1992. Determination of petroleum hydrocarbons in sediments. Reference Methods for Marine Pollution Studies 20, UNEP, 75 pp.

Venturini, N., Tommasi, L.R., Bicego, M.C. and Martins, C.C., 2004. Characterization of the Benthic Environment of a Coastal Area Adjacent to an Oil Refinery, Todos os Santos Bay (NE-Brazil). Brazilian Journal of Oceanography 52, 39-50.

Viguri, J., Verde, J., Irabien, A., 2002. Environmental assessment of polycyclic aromatic hydrocarbons (PAHs) in surface sediments of the Santander Bay. Northern Spain. Chemosphere 48, 157-165.

Volkman, J.K., Holdsworth, D.G., Neil, G.P., Bavor Jr., H.J., 1992. Identification of natural anthropogenic and petroleum hydrocarbons in aquatic sediments. Sci. Tot. Environ. 112, 203-219.

Wang, Z., Fingas, M., Landriault, M., Sigouin, L., Feng, Y., Mullin, J., 1997. Using systematic and comparative analytical data to identify the source of an unknown oil on contaminated birds. J. Chromatogr. A 775, 251-265.

Wang, Z., Fingas, M., Page, D.S., 1999. Oil spill identification. J. Chromatogr. A 843, 369411.

Wilcke, W., Krauss, M., Amelung, W., 2002. Carbon isotope signature of polycyclic aromatic hydrocarbons (PAHs): evidence for different sources in tropical and temperate environments? Environ. Sci. Technol. 36, 3530-3535.

Witt, G., Trost, E., 1999. Polycyclic aromatic hydrocarbon (PAHs) in sediment of the Baltic Sea and of the German coastal waters. Chemosphere 38, 1603-1614. 
Wurl, O., Obbard, J.P., 2004. A review of pollutants in the sea-surface microlayer (SML): a unique habitat for marine organisms. Mar. Pollut. Bull. 48, 1016-1030.

Xia, X., Wang, R., 2008. Effect of sediment particle size on polycyclic aromatic hydrocarbon biodegradation: importance of the sediment-water interface. Environ. Toxicol. Chem. 27, $119-125$.

Yu, Y., Li, Y., Guo, Z., Zou, H., 2016. Distribution and sources of n-alkanes in surface sediments of Taihu Lake, China. Archives of Environmental Protection 42, 49-55.

Yunker, M.B., Macdonald, R.W., Vingarzan, R., Mitchell, R.H., Goyette, D., Sylvestre, S., 2002. PAHs in the Fraser River basin: a critical appraisal of PAH ratios as indicators of PAH source and composition. Org. Geochem. 33, 489-515.

Zaghden, H., Kallel, M., Elleuch, B., Oudot, J., Saliot, A., 2007. Sources and distribution of aliphatic and polyaromatic hydrocarbons in sediments of Sfax, Tunisia, Mediterranean Sea. Mar. Chem. 105, 70-89.

Zaghden, H., Kallel, M., Elleuch, B., Oudot, J., Saliot, A., Sayadi, S., 2014. Evaluation of hydrocarbon pollution in marine sediments of Sfax coastal areas from the Gabes Gulf of Tunisia, Mediterranean Sea. Environ. Earth. Sci. DOI 10.1007/s12665-013-3023-6.

Zaghden, H., Louati, A., Kallel, M., Elleuch, B., Saliot, A. Oudot, J., 2005. Hydrocarbons in surface sediments from the Sfax coastal zone, (Tunisia) Mediterrranean Sea. Mar. Pollut. Bull. 50, 1287-1294.

Zhang, W., Zhang, S., Wan, C., Yue, D., Ye, Y., Wang, X., 2008. Source diagnostics of polycyclic aromatic hydrocarbons in urban road runoff, dust, rain and canopy throughfall. Environ. Pollut. 153, 594-601.

Zrafi-Nouira, I., Safi, N.M.D., Bahri, R., Mzoughi, N., Aissi, A., Ben Abdennebi, H., Saidane-Mosbahi, D., 2010. Distribution and Sources of Polycyclic Aromatic 
Hydrocarbons around a Petroleum Refinery Rejection Area in Jarzouna-Bizerte (Coastal Tunisia). Soil and Sediment Contamination: An International Journal 19, 292-306.

Zrafi, I., Hizem, L., Chalghmi, H., Ghrabi, A., Rouabhia, M., Saidane-Mosbahi, D., 2013. Aliphatic and Aromatic Biomarkers for Petroleum Hydrocarbon Investigation in Marine Sediment. J. Pet. Sci. Res. 2, 145-155. 


\section{Figure captions}

Figure 1. Location of the study stations along the Sfax-Kerkennah channel, in the Northern part of the Gulf of Gabès (Southeast Tunisia, Southern Mediterranean Sea). The blue dotted line delimited the Sfax-Kerkennah channel area. The detailed characteristics of the stations are provided in Table 1.

Figure 2. Spatial distribution of a) the concentration in TOC (in $\%$ for $1 \mathrm{~g}$ sed. dw), b) the isotopic signature of organic carbon $\left(\delta^{13} \mathrm{C}\right.$ in $\%$ ) , c) the concentration in total $n$-alkanes $(R$ in $\mu \mathrm{g} \mathrm{g}^{-1}$ sed. dw), d) the concentration in total ( $\left.\sum 17\right)$ PAHs (in $\mathrm{ng} \mathrm{g}^{-1}$ sed. dw), e) the $R /$ TOC ratio (in $\mathrm{mg} \mathrm{g}^{-1}$ ) and $\mathrm{f}$ ) the $\mathrm{PAH} / \mathrm{TOC}$ ratio (in $\mu \mathrm{g} \mathrm{g}^{-1}$ ) in surficial sediments of the SfaxKerkennah channel (Ocean Data View software version 4.6.5, Schlitzer, R., http://odv.awi.de, 2014.).

Figure 3. Distribution pattern of PAHs in the surficial sediments of the Sfax-Kerkennah channel. 1-ring compound: Thi; 2-ring compounds: Nap and $\sum$ MeNap; 3-ring compounds: Phe, $\sum$ MePhe, Ant, $\sum$ MeAnt; 4-ring compounds: Flt, Pyr, $\sum \mathrm{MePyr}, \mathrm{BaA}$, Chr, $\sum \mathrm{MeChr}$; 5ring compounds: $\mathrm{BkF}, \mathrm{BaP}$, Per; 6-ring compounds: $\mathrm{BgP}$.

Figure 4. Cross plot of $\sum \mathrm{LMW} / \sum \mathrm{HMW}$ versus Flt/Flt+Pyr ratios for the different samples, except stations R106, R209 and R210, for which Flt/Flt+Pyr could not be determined. 
1 Table 1. Characteristics of the study stations, located along the Sfax-Kerkennah channel in the Northern part of the Gulf of

2 Gabès (Southeast Tunisia, Southern Mediterranean Sea), and sampled in January 2005.

\begin{tabular}{|c|c|c|c|c|c|}
\hline Station & Area & Position & $\begin{array}{l}\text { Depth of the } \\
\text { water column (m) }\end{array}$ & Type of bottom & $\overline{4}$ \\
\hline R101 & North of Sfax - Sidi Mansour & $34^{\circ} 48^{\prime} 52^{\prime \prime} \mathrm{N}, 10^{\circ} 53^{\prime} 05^{\prime \prime} \mathrm{E}$ & 1 & Dense meadows of Posidonia & \\
\hline R102 & & $34^{\circ} 47^{\prime} 56^{\prime \prime} \mathrm{N}, 10^{\circ} 54^{\prime} 00^{\prime \prime} \mathrm{E}$ & 1.1 & Meadows of Posidonia & 6 \\
\hline R103 & & $34^{\circ} 47^{\prime} 19^{\prime \prime} \mathrm{N}, 10^{\circ} 54^{\prime} 30^{\prime \prime} \mathrm{E}$ & 1.7 & Meadows of Posidonia & 7 \\
\hline R104 & Channel & $34^{\circ} 46^{\prime} 00^{\prime \prime} \mathrm{N}, 10^{\circ} 54^{\prime} 57^{\prime \prime} \mathrm{E}$ & 7.6 & Muddy sand & \\
\hline R105 & Channel & $34^{\circ} 45^{\prime} 05^{\prime \prime} \mathrm{N}, 10^{\circ} 55^{\prime} 25^{\prime \prime} \mathrm{E}$ & 9.5 & Dense meadows of Posidonia & 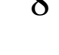 \\
\hline R106 & Channel & $34^{\circ} 44^{\prime} 08^{\prime \prime} \mathrm{N}, 10^{\circ} 55^{\prime} 50^{\prime \prime} \mathrm{E}$ & 8.5 & Sandy with Posidonia & 9 \\
\hline R107 & Channel & $34^{\circ} 43^{\prime} 08^{\prime \prime} \mathrm{N}, 10^{\circ} 56^{\prime} 20^{\prime \prime} \mathrm{E}$ & 5.5 & Dense meadows of Posidonia & 10 \\
\hline R108 & & $34^{\circ} 42^{\prime} 10^{\prime \prime} \mathrm{N}, 10^{\circ} 56^{\prime} 48^{\prime \prime} \mathrm{E}$ & 2.8 & Dense meadows of Posidonia & \\
\hline R109 & & $34^{\circ} 41^{\prime} 10^{\prime \prime} \mathrm{N}, 10^{\circ} 57^{\prime} 18^{\prime \prime} \mathrm{E}$ & 1 & Dense meadows of Posidonia & 11 \\
\hline R110 & & $34^{\circ} 40^{\prime} 19^{\prime \prime} \mathrm{N}, 10^{\circ} 57^{\prime} 43^{\prime \prime} \mathrm{E}$ & 0.8 & Muddy sand & 12 \\
\hline R111 & Kerkennah harbor & $34^{\circ} 39^{\prime} 26^{\prime \prime} \mathrm{N}, 10^{\circ} 58^{\prime} 00^{\prime \prime} \mathrm{E}$ & 2.7 & Sandy with Posidonia & \\
\hline R210 & Channel & $34^{\circ} 40^{\prime} 19^{\prime \prime} \mathrm{N}, 10^{\circ} 56^{\prime} 05^{\prime \prime} \mathrm{E}$ & 7 & Sandy & 13 \\
\hline R209 & Channel & $34^{\circ} 40^{\prime} 52^{\prime \prime} \mathrm{N}, 10^{\circ} 55^{\prime} 05^{\prime \prime} \mathrm{E}$ & 9 & Meadows of Posidonia & 14 \\
\hline R208 & Channel & $34^{\circ} 41^{\prime} 25^{\prime \prime} \mathrm{N}, 10^{\circ} 54^{\prime} 00^{\prime \prime} \mathrm{E}$ & 15.7 & Meadows of Posidonia & 15 \\
\hline R207 & Channel & $34^{\circ} 41^{\prime} 48^{\prime \prime} \mathrm{N}, 10^{\circ} 52^{\prime} 55^{\prime \prime} \mathrm{E}$ & 20 & Meadows of Posidonia & \\
\hline R205 & Channel & $34^{\circ} 42^{\prime} 15^{\prime \prime} \mathrm{N}, 10^{\circ} 50^{\prime} 28^{\prime \prime} \mathrm{E}$ & 7.3 & Muddy sand & 16 \\
\hline R204 & Channel & $34^{\circ} 42^{\prime} 23^{\prime \prime} \mathrm{N}, 10^{\circ} 49^{\prime} 15^{\prime} \mathrm{E}$ & 8.5 & Muddy sand & 17 \\
\hline R203 & Channel & $34^{\circ} 42^{\prime} 31^{\prime \prime} \mathrm{N}, 10^{\circ} 48^{\prime} 00^{\prime \prime} \mathrm{E}$ & 7.9 & Muddy sand & \\
\hline R202 & & $34^{\circ} 42^{\prime} 39^{\prime \prime} \mathrm{N}, 10^{\circ} 46^{\prime} 50^{\prime \prime} \mathrm{E}$ & 4 & Muddy sand & 18 \\
\hline R201 & Sfax harbor & $34^{\circ} 42^{\prime} 46^{\prime \prime} \mathrm{N}, 10^{\circ} 46^{\prime} 05^{\prime \prime} \mathrm{E}$ & 4.5 & Muddy sand & 19 \\
\hline
\end{tabular}


Table 2. Hydrocarbon molecular diagnostic ratios investigated in this study with typical values from the literature. Adapted from Tobiszewski and Namieśnik (2012) and Katsoyiannis and Breivik (2014).

\begin{tabular}{|c|c|c|c|c|}
\hline \multirow{2}{*}{$\begin{array}{l}\text { Hydrocarbons } \\
\text { AHs }\end{array}$} & \multirow[t]{2}{*}{ Ratios } & \multicolumn{2}{|c|}{ Hydrocarbon origin } & \multirow[t]{2}{*}{ References } \\
\hline & & Recent/less degraded & Degraded & \\
\hline & $\mathrm{UCM} / R$ & - & $>3-4$ & Simoneit and Mazurek (1982); Mazurek and \\
\hline & $n-\mathrm{C}_{17} / \mathrm{Pr}$ & $>1$ & $<1$ & Simoneit (1984); Asia et al. (2009) \\
\hline & $n-\mathrm{C}_{18} /$ Phy & $>1$ & $<1$ & \\
\hline & & Biogenic & Petrogenic & \\
\hline & $\mathrm{Pr} / \mathrm{Phy}$ & $>1$ & - & Rieley et al. (1991); Wang et al. (1999); \\
\hline & $\mathrm{CPI}_{15-24}$ & $>>$ or $<<1$ & $\sim 1$ & Commendatore and Esteves (2004); Harji et al. \\
\hline & $\mathrm{CPI}_{25-34}$ & $>>$ or $<<1$ & $\sim 1$ & \\
\hline & & Terrestrial higher plants & Algae, phyto-, zoo-plankton & \\
\hline & TAR & $>1$ & $<1$ & $\begin{array}{l}\text { Bourbonniere and Meyers (1996); Mille et al. } \\
\text { (2007) }\end{array}$ \\
\hline \multirow[t]{9}{*}{ PAHs } & & Petrogenic & Pyrogenic & \\
\hline & $\sum \mathrm{LMW} / \Sigma \mathrm{HMW}$ & $>1$ & $<1$ & Soclo et al. (2000); Zhang et al. (2008) \\
\hline & $\sum \mathrm{MePhe} / \mathrm{Phe}$ & $>2$ & $<2$ & Prahl and Carpenter (1983); Garrigues et al. (1995) \\
\hline & $\sum \mathrm{MePyr} / \mathrm{Pyr}$ & $>1$ & $<1$ & Zaghden et al. $(2007 ; 2014)$ \\
\hline & $\mathrm{Flt} / \mathrm{Flt}+\mathrm{Pyr}$ & $<0.4$ & $>0.4$ & Yunker et al. (2002); Li et al. (2006) \\
\hline & & Fuel combustion & Grass/coal/wood combustion & \\
\hline & $\mathrm{Flt} / \mathrm{Flt}+\mathrm{Pyr}$ & $0.4-0.5$ & $>0.5$ & De La Torre-Roche et al. (2009) \\
\hline & & Non-traffic emissions & Traffic emissions & \\
\hline & $\mathrm{BaP} / \mathrm{BgP}$ & $<0.6$ & $>0.6$ & Katsoyiannis et al. (2007) \\
\hline
\end{tabular}


Table 3. Granulometric parameters ( $\mathrm{Mz}$ and $\sigma$ in unit $\phi$ ), percentages (for $1 \mathrm{~g}$ sediment dry weight) of elemental constituents $(\mathrm{C}, \mathrm{H}, \mathrm{N}, \mathrm{S})$, calcium carbonate $\left(\mathrm{CaCO}_{3}\right)$ and total organic carbon (TOC), isotopic signature of organic carbon $\left(\delta^{13} \mathrm{C}\right.$ in \%o), and concentrations in total $n$-alkanes $\left(R\right.$ in $\mu \mathrm{g} \mathrm{g}^{-1}$ sed. $\mathrm{dw}$ ) and associated molecular diagnostic ratios (UCM/R, CPI, Pr/Phy, $n-\mathrm{C}_{17} / \mathrm{Pr}, n-\mathrm{C}_{18} / \mathrm{Phy}$, TAR) in the fraction $<63 \mu \mathrm{m}$ of surficial sediments $(0-$

\begin{tabular}{|c|c|c|c|c|c|c|c|c|c|c|c|c|c|c|c|c|c|c|c|c|}
\hline & R101 & R102 & R103 & R104 & R105 & R106 & R107 & R108 & R109 & R110 & R111 & $\mathbf{R 2 1 0}$ & R209 & R208 & R207 & R205 & R204 & $\mathbf{R 2 0 3}$ & $\overline{\mathrm{R202}}$ & R201 \\
\hline $\mathbf{M z}(\phi)$ & 3 to 2 & 3 to 2 & 3 to 2 & 4 to 3 & 2 to 1 & 3 to 2 & 2 to 1 & 3 to 2 & 3 to 2 & 3 to 2 & 4 to 3 & 3 to 2 & 2 to 1 & 2 to 1 & 2 to 1 & 2 to 1 & 2 to 1 & 2 to 1 & 3 to 2 & 4 to 3 \\
\hline$\sigma(\phi)$ & 2 to 1 & 2 to 1 & 2 to 1 & 2 to 1 & 2 to 1 & 2 to 1 & 2 to 1 & 2 to 1 & 2 to 1 & 2 to 1 & 2 to 1 & 2 to 1 & 2 to 1 & 2 to 1 & 2 to 1 & 2 to 1 & 2 to 1 & 2 to 1 & 2 to 1 & 2 to 1 \\
\hline $\mathrm{C}(\%)$ & 9.3 & 10.3 & 11.1 & 13.0 & 12.1 & 11.8 & 11.9 & 12.6 & 12.7 & 12.7 & 12.7 & 12.3 & 12.7 & 11.7 & 11.6 & 12.1 & 10.8 & 9.4 & 7.9 & 14.6 \\
\hline H (\%) & 0.73 & 0.73 & 0.99 & 1.22 & 0.64 & 0.62 & 0.60 & 0.76 & 0.67 & 0.73 & 0.75 & 0.71 & 0.71 & 0.65 & 0.61 & 0.75 & 0.65 & 0.58 & 0.57 & 1.91 \\
\hline $\mathbf{N}(\%)$ & 0.30 & 0.32 & 0.39 & 0.49 & 0.23 & 0.22 & 0.21 & 0.28 & 0.29 & 0.35 & 0.32 & 0.27 & 0.27 & 0.23 & 0.21 & 0.26 & 0.22 & 0.19 & 0.19 & 1.23 \\
\hline $\mathbf{S}(\%)$ & 0.54 & 0.62 & 0.67 & 0.61 & 0.47 & 0.50 & 0.10 & 0.52 & 0.44 & 0.48 & 0.60 & 0.75 & 0.42 & 0.31 & 0.37 & 0.41 & 0.31 & 0.29 & 0.84 & 1.33 \\
\hline $\operatorname{TOC}(\%)$ & 3.2 & 4.0 & 5.5 & 7.3 & 3.5 & 3.5 & 11.9 & 4.5 & 3.9 & 6.3 & 7.2 & 3.8 & 3.7 & 3.2 & 2.9 & 4.0 & 3.5 & 2.5 & 2.2 & 11.6 \\
\hline TOC/N & 10.8 & 12.5 & 14.0 & 14.9 & 15.2 & 15.7 & 56.6 & 16.0 & 13.3 & 18.0 & 22.3 & 14.0 & 13.6 & 13.7 & 13.8 & 15.3 & 15.7 & 13.3 & 11.4 & 9.4 \\
\hline TOC/S & 6.0 & 6.5 & 8.1 & 12.0 & 7.4 & 6.9 & 118.9 & 8.6 & 8.8 & 13.1 & 11.9 & 5.0 & 8.7 & 10.2 & 7.8 & 9.7 & 11.2 & 8.7 & 2.6 & 8.7 \\
\hline $\mathrm{CaCO}_{3}(\%)$ & 48.8 & 57.9 & 52.5 & 40.0 & 95.8 & 91.6 & 51.6 & 95.4 & 84.6 & 90.1 & 76.9 & 88.3 & 72.7 & 71.6 & 67.9 & 79.7 & 70.8 & 63.3 & 53.1 & 41.0 \\
\hline$\delta^{13} \mathbf{C}(\% o)$ & -20.9 & -21.2 & -22.4 & -23.7 & -24.6 & -25.1 & -25.1 & -24.4 & -22.7 & -23.6 & -22.2 & -24.7 & -25.2 & -25.4 & -25.0 & -25.0 & -25.4 & -25.5 & -24.8 & -24.0 \\
\hline$R\left(\mu \mathrm{g} \mathrm{g}^{-1}\right)$ & 29.4 & 14.2 & 22.8 & 45.7 & 10.3 & 8.1 & 14.1 & 18.7 & 23.5 & 24.2 & 72.1 & 18.1 & 12.7 & 10.2 & 33.5 & 15.7 & 15.9 & 16.8 & 20.6 & 173.9 \\
\hline $\mathrm{UCM} / \boldsymbol{R}$ & 1.6 & 1.5 & 0.9 & 2.7 & 2.0 & 3.1 & 2.5 & 2.3 & 1.9 & 1.9 & 3.8 & 3.5 & 4.6 & 4.8 & 1.2 & 2.7 & 2.8 & 2.9 & 5.7 & 5.0 \\
\hline $\mathrm{CPI}_{15-24}$ & 0.59 & 0.38 & 0.35 & 0.33 & 0.35 & 0.38 & 0.34 & 0.24 & 0.36 & 0.39 & 0.40 & 0.41 & 0.72 & 0.65 & 0.64 & 0.30 & 0.33 & 0.28 & 0.70 & 0.96 \\
\hline $\mathrm{CPI}_{25-34}$ & 4.3 & 3.9 & 5.8 & 3.9 & 3.8 & 4.7 & 2.2 & 5.2 & 5.1 & 4.8 & 2.5 & 2.3 & 2.0 & 4.3 & 2.9 & 3.0 & 2.4 & 2.0 & 1.7 & 1.8 \\
\hline Pr/Phy & 0.36 & 0.59 & 0.73 & 0.49 & 0.68 & 0.39 & 0.91 & 0.64 & 0.43 & 1.19 & 0.29 & 0.70 & 2.85 & 1.47 & 0.39 & 0.73 & 0.82 & 0.35 & 0.64 & 1.23 \\
\hline$n-\mathrm{C}_{17} / \mathrm{Pr}$ & 4.5 & 0.7 & 1.3 & 4.9 & 1.1 & 4.3 & 3.1 & 1.5 & 4.3 & 1.0 & 5.2 & 3.9 & 1.1 & 1.5 & 3.1 & 3.5 & 1.3 & 3.0 & 3.0 & 1.4 \\
\hline$n-\mathrm{C}_{18} / \mathrm{Phy}$ & 3.0 & 3.2 & 4.5 & 5.4 & 3.7 & 4.1 & 9.0 & 4.1 & 4.7 & 4.7 & 3.2 & 7.5 & 6.3 & 4.1 & 2.5 & 7.3 & 3.9 & 4.0 & 1.8 & 1.7 \\
\hline TAR & 2.1 & 6.6 & 10.4 & 0.9 & 1.7 & 1.0 & 0.5 & 1.8 & 1.4 & 2.8 & 1.7 & 1.2 & 1.2 & 1.5 & 0.8 & 1.0 & 1.6 & 1.5 & 0.8 & 1.2 \\
\hline
\end{tabular}


36 Table 4. Comparison of total $n$-alkane concentrations $\left(R\right.$ in $\mu \mathrm{g} \mathrm{g}^{-1}$ sed. dw) in surficial/surface sediments from different regions of the

Mediterranean Sea.

\begin{tabular}{|c|c|c|c|c|c|}
\hline Country & Site & $\begin{array}{l}\text { Number of } \\
\text { samples/sites }\end{array}$ & $\begin{array}{l}n \text {-alkanes } \\
\text { analyzed }\end{array}$ & $\begin{array}{l}\text { Range } \\
\left(\mu \mathrm{g} \mathrm{g}^{-1} \text { sed. dw }\right)\end{array}$ & Reference \\
\hline \multirow[t]{6}{*}{ Tunisia } & Gulf of Gabès, Sfax-Kerkennah channel & 20 & $n-\mathrm{C}_{15}-n-\mathrm{C}_{34}$ & $8.1-174$ & This study \\
\hline & Gulf of Gabès, Sfax coastline and Kerkennah channel & 18 & $n-\mathrm{C}_{12}-n-\mathrm{C}_{34}$ & $2.2-430$ & Zaghden et al. (2007) \\
\hline & Gulf of Gabès, Gabès, Kettana, Al-Zar coastline & 9 & $n-\mathrm{C}_{14}-n-\mathrm{C}_{37}$ & $21-3,886$ & Amorri et al. (2011) \\
\hline & Sfax ponds & 5 & $n-\mathrm{C}_{13}-n-\mathrm{C}_{30}$ & $27-128$ & Elloumi et al. (2008) \\
\hline & Gulf of Tunis (Rades, Goulette, Sidi Bou Saïd harbors) & 12 & $n-\mathrm{C}_{10}-n-\mathrm{C}_{34}$ & $1.8-10$ & Mzoughi and Chouba (2011) \\
\hline & Khniss Coast & 12 & $n-\mathrm{C}_{9}-n-\mathrm{C}_{32}$ & $9.7-36.1$ & Zrafi et al. (2013) \\
\hline Morocco & Tangier coastal zone & 10 & $n-\mathrm{C}_{15}-n-\mathrm{C}_{38}$ & $0.4-15.6$ & Bouzid et al. (2012) \\
\hline \multirow[t]{4}{*}{ Egypt } & Eastern harbour of Alexandria & 15 & $n-\mathrm{C}_{13}-n-\mathrm{C}_{35}$ & $7-143$ & Aboul-Kassim and Simoneit (1995) \\
\hline & Coastal areas (bays, estuaries and harbors) & 31 & $n-\mathrm{C}_{7}-n-\mathrm{C}_{34}$ & $0.09-9.1$ & El Nemr et al. (2007) \\
\hline & Coastal areas (bays, estuaries and harbors) & 10 & $n-\mathrm{C}_{7}-n-\mathrm{C}_{34}$ & $0.5-1.6$ & El Nemr et al. (2013) \\
\hline & Abu Qir Bay & 20 & $n-\mathrm{C}_{10}-n-\mathrm{C}_{34}$ & $0.06-0.6$ & El Deeb et al. (2007) \\
\hline \multirow[t]{4}{*}{ France } & Rhône delta & 6 & $n-\mathrm{C}_{12}-n-\mathrm{C}_{34}$ & $10.1-27.1$ & Lipiatou and Saliot (1991b) \\
\hline & Gulf of Lions and Central Western Mediterranean & 5 & $n-\mathrm{C}_{12}-n-\mathrm{C}_{34}$ & $1.4-2.5$ & Lipiatou and Saliot (1991b) \\
\hline & Gulf of Fos-sur-mer & 11 & $n-\mathrm{C}_{14}-n-\mathrm{C}_{32}$ & $0.5-6.9$ & Mille et al. (2007) \\
\hline & Berre Lagoon & 2 & $n-\mathrm{C}_{14}-n-\mathrm{C}_{34}$ & $1.4-3.6$ & Kanzari et al. (2012) \\
\hline Italy & Gulf of Trieste & 8 & $n-\mathrm{C}_{14}-n-\mathrm{C}_{34}$ & $2.0-4.9$ & Bajt (2014) \\
\hline Spain & Ebro shelf and slope, Catalan coast & 5 & $n-\mathrm{C}_{14}-n-\mathrm{C}_{40}$ & $0.3-1.1$ & Tolosa et al. (1996) \\
\hline \multirow[t]{3}{*}{ Greece } & Patroklos and Sitia areas & 15 & $n-\mathrm{C}_{11}-n-\mathrm{C}_{35}$ & $1.6-32.3$ & Tsapakis et al. (2010) \\
\hline & Cretan Sea & 10 & $n-\mathrm{C}_{15}-n-\mathrm{C}_{40}$ & $0.08-0.90$ & Gogou et al. (2000) \\
\hline & Cretan Sea & 52 & $n-\mathrm{C}_{17}-n-\mathrm{C}_{41}$ & $0.22-3.8$ & Mandalakis et al. (2014) \\
\hline \multirow[t]{2}{*}{ Turkey } & Aliağa Bay (Aegean Sea) & 15 & $n-\mathrm{C}_{10}-n-\mathrm{C}_{34}$ & $0.34-56.5$ & Neşer et al. (2012) \\
\hline & Coastal Aegean Sea & 12 & $n-\mathrm{C}_{12}-n-\mathrm{C}_{35}$ & $0.25-2.4$ & Gonul and Kucuksezgin (2012) \\
\hline
\end{tabular}


39 Table 5. Concentrations in polycyclic aromatic hydrocarbons (PAHs in $\mathrm{ng} \mathrm{g}^{-1}$ sed. $\mathrm{dw}$ ) and associated molecular diagnostic ratios in the fraction < $63 \mu \mathrm{m}$ of

40 surficial sediments $(0-1 \mathrm{~cm})$ collected along the Sfax-Kerkennah channel (Southeast Tunisia, Southern Mediterranean Sea).

41

\begin{tabular}{|c|c|c|c|c|c|c|c|c|c|c|c|c|c|c|c|c|c|c|c|c|}
\hline & R101 & R102 & R103 & R104 & R105 & R106 & R107 & R108 & R109 & R110 & R111 & $\mathbf{R 2 1 0}$ & R209 & R208 & R207 & R205 & R204 & R203 & R202 & R201 \\
\hline Nap & bld & bld & bld & bld & bld & bld & bld & bld & bld & bld & bld & bld & bld & bld & bld & bld & 56.1 & bld & 43.1 & bld \\
\hline$\sum$ MeNap & bld & bld & bld & bld & bld & bld & bld & bld & bld & bld & bld & bld & bld & bld & bld & bld & 79.7 & bld & 42.7 & bld \\
\hline Phe & 8.9 & 39.2 & 13.9 & 10.9 & 13.8 & 9.9 & 11.9 & 9.9 & 35.2 & 38.5 & 35.8 & 19.7 & 12.6 & 9.8 & 12.7 & 25.5 & 205.7 & 79.5 & 63.6 & 179.4 \\
\hline$\sum$ MePhe & 78.9 & 155.2 & 98.3 & 29.9 & 39.7 & 93.9 & 89.6 & 30.0 & 47.0 & 247.9 & 314.7 & 29.5 & 59.7 & 21.6 & 102.8 & 96.6 & 457.5 & 401.9 & 497.9 & 940.1 \\
\hline Ant & bld & bld & bld & bld & bld & bld & bld & bld & bld & bld & bld & bld & 15.0 & bld & bld & bld & 169.3 & bld & 151.7 & bld \\
\hline$\sum$ MeAnt & 58.8 & bld & bld & bld & 19.7 & 49.0 & bld & 62.2 & bld & 104.7 & bld & 13.0 & bld & bld & bld & 130.2 & 198.4 & 283.9 & 251.5 & bld \\
\hline Thi & 30.1 & bld & 12.9 & 25.1 & 12.9 & 28.8 & bld & 6.6 & bld & 140.9 & 118.4 & 15.6 & bld & bld & bld & 28.5 & 258.2 & 324.2 & 362.7 & 1344 \\
\hline Flt & 25.2 & 22.8 & 15.6 & 53.1 & 15.6 & bld & 27.3 & 22.3 & 5.3 & 126.6 & 100.6 & bld & bld & 29.4 & 69.4 & 15.2 & 54.6 & 251.7 & 396.6 & 601.8 \\
\hline Pyr & 87.6 & 54.1 & 82.7 & 248.2 & 65.6 & 42.5 & 74.7 & 28.1 & 9.8 & 248.2 & 350.3 & 65.6 & 14.0 & 10.4 & 100.2 & 221.8 & 56.4 & 364.6 & 500.9 & 1752 \\
\hline$\sum$ MePyr & 103.1 & 128.3 & 87.8 & 297.7 & 124.5 & 60.5 & 58.4 & 42.5 & 19.6 & 387.9 & 412.2 & 120.5 & bld & 19.6 & 126.2 & 57.4 & 102.7 & 434.6 & 412.9 & 2675 \\
\hline $\mathbf{B a A}$ & bld & bld & 26.4 & bld & bld & bld & bld & bld & bld & bld & bld & bld & bld & bld & bld & bld & bld & 71.9 & bld & bld \\
\hline Chr & 62.3 & 63.9 & 72.1 & 190.6 & 188.3 & 50.5 & 27.2 & 50.2 & 11.0 & 190.6 & 249.5 & 188.3 & 13.9 & 29.1 & 34.3 & 302.0 & 138.6 & 248.3 & 171.3 & 1246 \\
\hline$\sum$ MeChr & 78.2 & 43.8 & 105.7 & 239.0 & 100.0 & 81.5 & bld & 75.6 & bld & 178.6 & 313.6 & 188.0 & bld & 11.3 & bld & bld & 159.8 & 326.8 & 162.9 & 993.7 \\
\hline BkF & 18.6 & 50.2 & bld & bld & 94.9 & 31.8 & 26.3 & 24.8 & 7.9 & 136.5 & 74.3 & 146.7 & bld & 7.9 & 49.9 & 32.2 & 126.1 & 144.6 & 853.7 & bld \\
\hline BaP & bld & 113.0 & 18.7 & 101.7 & 60.1 & 42.2 & 18.5 & 39.8 & 8.8 & 101.7 & 119.3 & 60.1 & 68.3 & 8.8 & 38.4 & 30.8 & bld & 144.5 & 192.0 & 113.9 \\
\hline Per & 22.7 & 68.9 & 64.3 & 107.3 & 49.9 & 21.9 & 41.5 & 232.0 & 16.7 & 40.3 & 92.8 & 52.7 & 43.6 & 18.9 & 125.7 & 28.2 & 86.2 & 129.5 & 241.5 & 620.5 \\
\hline BgP & bld & 46.7 & 36.2 & 80.5 & 90.8 & 34.1 & 28.4 & 34.1 & 83.9 & 80.5 & 60.6 & bld & bld & 7.8 & 21.2 & 14.8 & 97.6 & 147.6 & 105.9 & 303.1 \\
\hline$\sum 17$ PAHs & 574.4 & 786.1 & 634.6 & 1384 & 875.8 & 546.6 & 403.8 & 658.0 & 245.2 & 2023 & 2242 & 899.7 & 227.1 & 174.5 & 680.8 & 983.2 & 2247 & 3354 & 4451 & 10769 \\
\hline$\sum \mathbf{L M W} / \sum \mathbf{H M W}$ & 0.37 & 0.33 & 0.22 & 0.03 & 0.09 & 0.42 & 0.34 & 0.19 & 0.50 & 0.26 & 0.20 & 0.08 & 0.62 & 0.22 & 0.20 & 0.36 & 1.42 & 0.34 & 0.35 & 0.13 \\
\hline$\sum$ MePhe/Phe & 8.9 & 4.0 & 7.1 & 2.7 & 2.9 & 9.5 & 7.5 & 3.0 & 1.3 & 6.4 & 8.8 & 1.5 & 4.7 & 2.2 & 8.1 & 3.8 & 2.2 & 5.1 & 7.8 & 5.2 \\
\hline$\sum$ MePyr/Pyr & 1.2 & 2.4 & 1.1 & 1.2 & 1.9 & 1.4 & 0.8 & 1.5 & 2.0 & 1.6 & 1.2 & 1.8 & nd & 1.9 & 1.3 & 0.3 & 1.8 & 1.2 & 0.8 & 1.5 \\
\hline Flt/Flt+Pyr & 0.22 & 0.30 & 0.16 & 0.18 & 0.19 & nd & 0.27 & 0.44 & 0.35 & 0.34 & 0.22 & nd & nd & 0.74 & 0.41 & 0.06 & 0.49 & 0.41 & 0.44 & 0.26 \\
\hline BaP/BgP & nd & 2.42 & 0.52 & 1.26 & 0.66 & 1.24 & 0.65 & 1.17 & 0.10 & 1.26 & 1.97 & nd & nd & 1.13 & 1.81 & 2.08 & nd & 0.98 & 1.81 & 0.38 \\
\hline
\end{tabular}

42 bld: below detection limit; nd: not determined. 
Table 6. Comparison of total PAH concentrations (in $\mathrm{ng} \mathrm{g}^{-1}$ sed. $\mathrm{dw}$ ) in surficial/surface sediments from different regions of the Mediterranean Sea.

\begin{tabular}{|c|c|c|c|c|c|c|}
\hline Country & Site & $\begin{array}{l}\text { Number of } \\
\text { samples/sites }\end{array}$ & $\begin{array}{l}\text { Number of } \\
\text { PAHs } \\
\text { analyzed }\end{array}$ & $\begin{array}{l}\text { Range } \\
\left(\text { ng g }^{-1} \text { sed. dw }\right)\end{array}$ & Pollution level $^{\mathrm{a}}$ & Reference \\
\hline \multirow[t]{11}{*}{ Tunisia } & Gulf of Gabès, Sfax-Kerkennah channel & 20 & 17 & $175-10,769$ & Moderate to very high & This study \\
\hline & Gulf of Gabès, Sfax coastline and Kerkennah channel & 18 & 17 & $113-10,720$ & Moderate to very high & Zaghden et al. (2007) \\
\hline & Gulf of Gabès, Sfax coastline & 9 & 16 & $811-5,608$ & Moderate to very high & Zaghden et al. (2014) \\
\hline & Gulf of Tunis (Rades, Goulette, Sidi Bou Saïd harbors) & 12 & 22 & $363-7,026$ & Moderate to very high & Mzoughi and Chouba (2011) \\
\hline & Jarzouna-Bizerte coastal area & 4 & 17 & $916-3,146$ & Moderate to high & Zrafi-Nouira et al. (2010) \\
\hline & Coasts of Sfax, Luza, Khniss and Sousse & 4 & 14 & $160-1,990$ & Moderate to high & Kessabi et al. (2013) \\
\hline & Ghar El Melh Lagoon & 12 & 17 & $40-655$ & Low to moderate & Ben Ameur et al. (2010) \\
\hline & Bizerte Lagoon & 6 & 16 & $2-537$ & Low to moderate & Louiz et al. (2008) \\
\hline & Bizerte Lagoon & 10 & 16 & $83-447$ & Low to moderate & Trabelsi and Driss (2005) \\
\hline & Bizerte Lagoon & 18 & 14 & $17-394$ & Low to moderate & Barhoumi et al. (2014) \\
\hline & Khniss coast & 12 & 17 & $7-15$ & Low & Zrafi et al. (2013) \\
\hline Morocco & Al Hoceïma coastal area (effluent outfall and harbor) & 22 & - & $15-551$ & Low to moderate & Pavoni et al. (2003) \\
\hline \multirow[t]{5}{*}{ Egypt } & Coastal areas (bays, estuaries and harbors) & 26 & 16 & $3.5-14,100$ & Low to very high & Barakat et al. (2011) \\
\hline & Coastal areas (bays, estuaries and harbors) & 31 & 16 & $88-6,338$ & Low to very high & El Nemr et al. (2007) \\
\hline & Coastal areas (bays, estuaries and harbors) & 10 & 15 & $209-1,020$ & Moderate to high & El Nemr et al. (2013) \\
\hline & Abu Qir Bay & 20 & 16 & bld-2,660 & Low to high & Khairy et al. (2009) \\
\hline & Abu Qir Bay & 20 & 11 & $69-1,464$ & Low to high & El Deeb et al. (2007) \\
\hline \multirow[t]{6}{*}{ France } & Lazaret Bay & 5 & 14 & $1440-48,090$ & High to very high & Benlahcen et al. (1997) \\
\hline & Rhône Delta & 15 & 9 & $1070-6,330$ & High to very high & Bouloubassi and Saliot (1993) \\
\hline & Port Vendres harbor & 2 & 14 & $150-6,900$ & Moderate to very high & Baumard et al. (1998) \\
\hline & Gulf of Fos-sur-mer & 11 & 13 & $34-13,780$ & Low to very high & Mille et al. (2007) \\
\hline & Berre Lagoon & 2 & 16 & $334-853$ & Moderate & Kanzari et al. (2012) \\
\hline & Bay of Banuyls-sur-mer & 2 & 10 & $21-23$ & Low & Charles et al. (2012) \\
\hline \multirow[t]{4}{*}{ Italy } & Taranto Gulf & 10 & 16 & $28,918-262,446$ & Very high & Annicchiarico et al. (2011) \\
\hline & Coastal Ligurian Sea & 12 & 16 & $2875-26,247$ & High to very high & Bertolotto et al. (2003) \\
\hline & Venice Lagoon & 6 & 6 & $65-48,000$ & Low to very high & La Rocca et al. (1996) \\
\hline & Naples harbor & 189 & 16 & $9-31,774$ & Low to very high & Sprovieri et al. (2007) \\
\hline
\end{tabular}


Gulf of Trieste

Marano and Grado Lagoons

Gulf of Trieste

Chioggia and Ancona coastal zones

Spain

Barcelona harbor

Barcelona harbor

Santander Bay

Catalonia coast

Cap Salou, Cap Roig

Greece Gulf of Corinth, North Evoikos and Saronikos Gulfs

Drapetsona-Keratsini coastal zone

Patroklos and Sitia areas

North Aegean Sea

Cretan Sea

\section{Cretan Sea}

Turkey

Izmit Bay

Aliağa Bay (Aegean Sea)

Coastal Aegean Sea

Candarli Gulf

Croatia Northern Adriatic (Rovinj coastal area)

Northern Adriatic (Rijeka Bay)
16

16

22

16

14

16

16

16

14

21

26

14

21

25

64

14

24

19

12

16

16
214-4,416

$50-1,026$

35-682

24-500

1,700-8,400

300-10,320

20-344,600

$13-16,700$

$5-840$

115-26,633

929-18,907

2.1-181

44-166

15-162

9-60

$118-11,435$

70-20,940

74-2,170

bld-405

32-13,681

$5-12,532$

5-271
Moderate to high

Low to high

Low to moderate

Low to moderate

Moderate to very high

Moderate to very high

Low to very high

Low to very high

Low to moderate

Moderate to very high

Moderate to very high

Low to moderate

Low to moderate

Low to moderate

Low

Moderate to very high

Low to very high

Low to high

Low to moderate

Low to very high

Low to very high

Low to moderate
Bajt (2014)

Acquavita et al. (2014)

Notar et al. (2001)

Magi et al. (2002)

Baumard et al. (1998)

Martínez-Lladó et al. (2007)

Viguri et al. (2002)

Eljarrat et al. (2001)

Baumard et al. (1998)

Botsou and Hatzianestis (2012)

Kapsimalis et al. (2014)

Tsapakis et al. (2010)

Papadopoulou and Samara (2002)

Gogou et al. (2000)

Mandalakis et al. (2014)

Tolun et al. (2006)

Neşer et al. (2012)

Gonul and Kucuksezgin (2012)

Kucuksezgin et al. (2012)

Bihari et al. (2006)

Alebic-Juretic (2011)

Kucuksezgin et al. (2013)

${ }^{\mathrm{a}}$ The pollution levels are those defined by Baumard et al. (1998): low, 0-100 $\mathrm{ng} \mathrm{g}^{-1}$; moderate, 100-1,000 $\mathrm{ng} \mathrm{g}^{-1}$; high, 1,000-5,000 ng g $\mathrm{g}^{-1}$; very high, > 5,000 ng $\mathrm{g}^{-1}$; bld: below detection limit. 
Table 7. Concentration ranges of PAHs in surficial sediments of the Sfax-Kerkennah channel (Southeast Tunisia, Southern Mediterranean Sea) and toxicity guidelines (in ng g ${ }^{-1}$ sed. dw); SQG: Sediment Quality Guidelines; ERL: Effects Range Low; ERM: Effects Range Median.

\begin{tabular}{|c|c|c|c|c|c|c|}
\hline & \multicolumn{2}{|c|}{ SQG $^{\mathrm{a}}$} & \multirow{2}{*}{$\begin{array}{l}\text { Concentration range } \\
\text { (this study) }\end{array}$} & \multirow{2}{*}{$\begin{array}{l}\text { Stations } \\
<\text { ERL }\end{array}$} & \multirow{2}{*}{$\begin{array}{c}\text { Stations } \\
\text { ERL-ERM }\end{array}$} & \multirow{2}{*}{$\begin{array}{l}\text { Stations } \\
>\text { ERM }\end{array}$} \\
\hline & ERL & ERM & & & & \\
\hline Nap & 160 & 2,100 & bld- $136^{\mathrm{b}}$ & All & - & - \\
\hline Phe & 240 & 1,500 & $31-1,120^{\mathrm{b}}$ & R101-R109, R205-R210 & R110, R111, R201-204 & - \\
\hline Ant & 85 & 1,100 & bld $-403^{\mathrm{b}}$ & $\begin{array}{l}\text { R101-R109, R111, R201, } \\
\text { R207-R210 }\end{array}$ & R110, R202-R205 & - \\
\hline Flt & 600 & 5,100 & bld-602 & All except R201 & R201 & - \\
\hline Chr & 384 & 2,800 & $11-2240^{\mathrm{b}}$ & $\begin{array}{l}\text { R101-R103, R105-R110, } \\
\text { R202, R204-R210 }\end{array}$ & R104, R111, R201, R203 & - \\
\hline BkF & na & na & bld-854 & - & - & - \\
\hline BaP & 430 & 1600 & bld-192 & All & - & - \\
\hline Per & na & na & $17-621$ & - & - & - \\
\hline$\sum \mathbf{P A H s}$ & 4,022 & 44,792 & $175-10,769^{b}$ & All except R201, R202 & R201, R202 & - \\
\hline
\end{tabular}

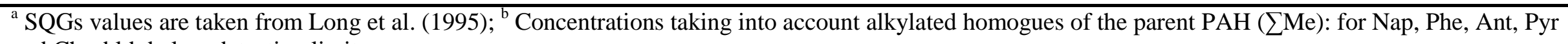
and $\mathrm{Chr}$; bld: below detection limit. 
Table 8. Pearson correlation matrices ( $\mathrm{r}$ values) for the main sediment parameters, taken into account all stations ( $\mathrm{n}=$ 20) or excluding station R107 ( $\mathrm{n}=19)$, stations R107 and R201 ( $\mathrm{n}=18)$ and stations R107, R201, R104, R110, R111, R202-R204 ( $=12)$. Significant correlations $(\mathrm{p}<0.05)$ are in bold.

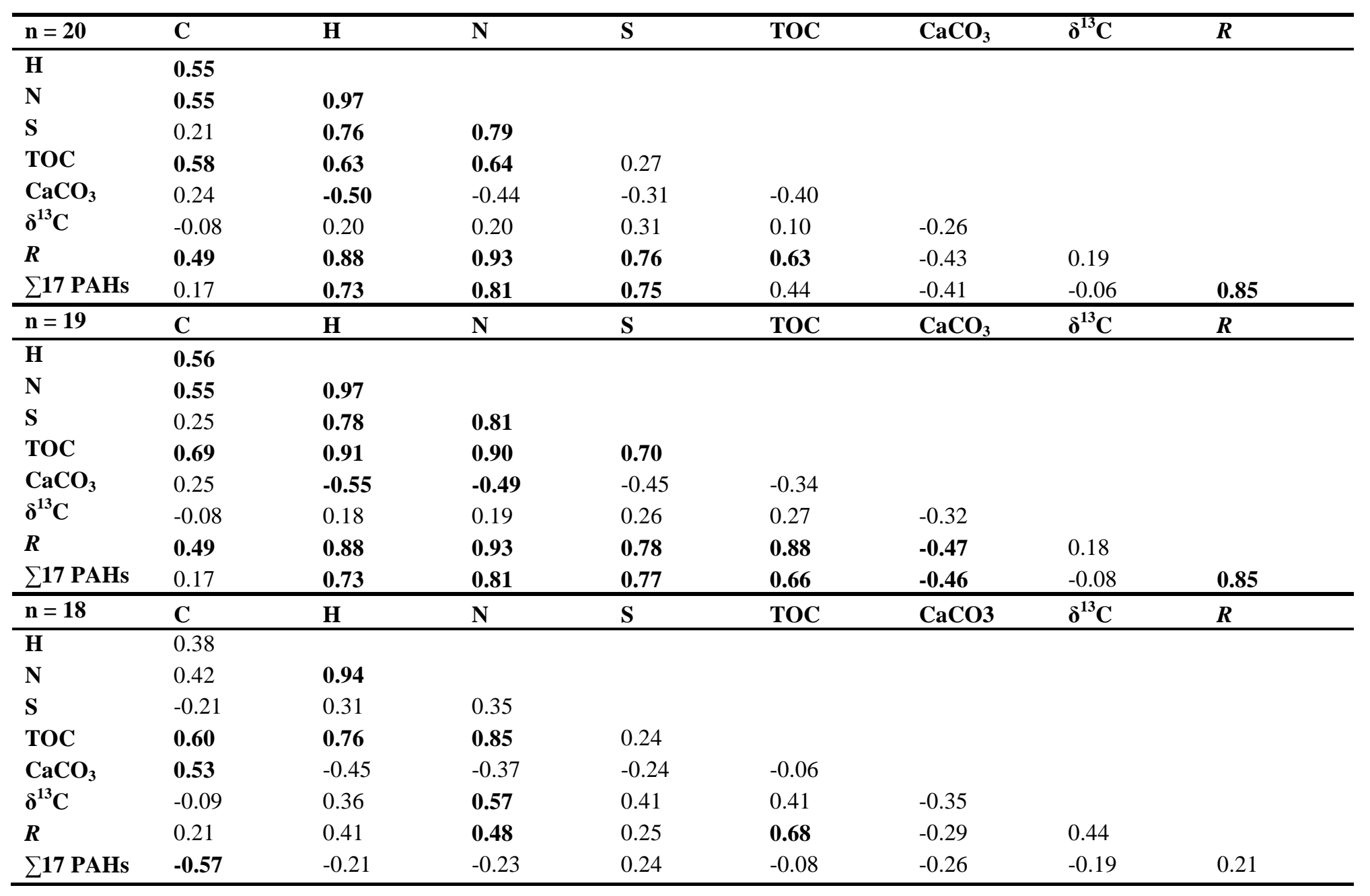




\begin{tabular}{llllllll}
\hline $\mathbf{n}=\mathbf{1 2}$ & $\mathbf{C}$ & $\mathbf{H}$ & $\mathbf{N}$ & $\mathbf{S}$ & $\mathbf{T O C}$ & $\mathbf{C a C O}_{\mathbf{3}}$ & $\boldsymbol{\delta}^{\mathbf{1 3}} \mathbf{C}$ \\
\hline $\mathbf{H}$ & -0.20 & & & & & & \\
$\mathbf{N}$ & -0.34 & $\mathbf{0 . 9 0}$ & & & & & \\
$\mathbf{S}$ & -0.26 & 0.54 & $\mathbf{0 . 6 3}$ & & & & \\
$\mathbf{T O C}$ & 0.10 & $\mathbf{0 . 9 0}$ & $\mathbf{0 . 8 2}$ & 0.55 & & & \\
$\mathbf{C a C O}_{\mathbf{3}}$ & $\mathbf{0 . 7 8}$ & -0.46 & -0.56 & -0.13 & -0.11 & & \\
$\boldsymbol{\delta}^{\mathbf{1 3}}$ & $\mathbf{- 0 . 7 4}$ & 0.43 & $\mathbf{0 . 7 3}$ & 0.47 & 0.30 & $\mathbf{- 0 . 6 5}$ & \\
$\boldsymbol{R}$ & -0.35 & 0.19 & 0.25 & 0.09 & -0.02 & -0.49 & 0.42 \\
$\sum \mathbf{1 7}$ PAHs & -0.15 & 0.16 & 0.04 & 0.48 & 0.18 & 0.14 & 0.05 \\
\hline
\end{tabular}




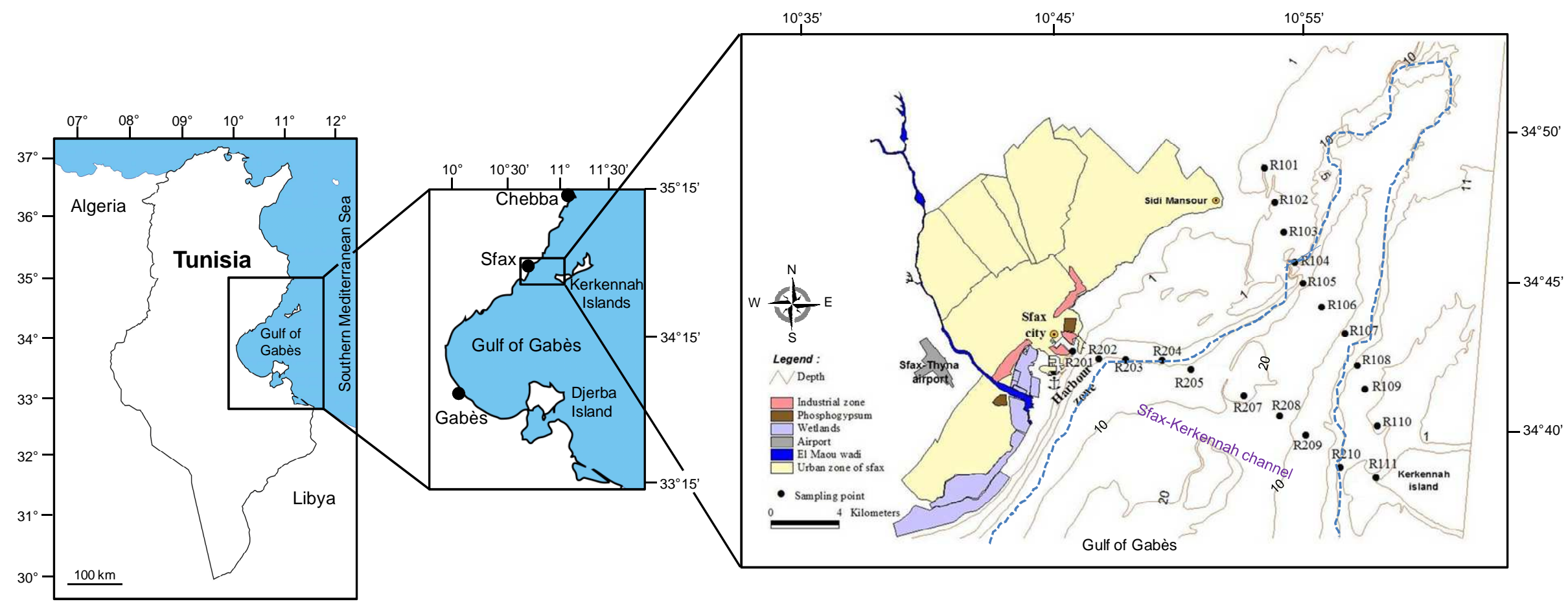

Figure 1 

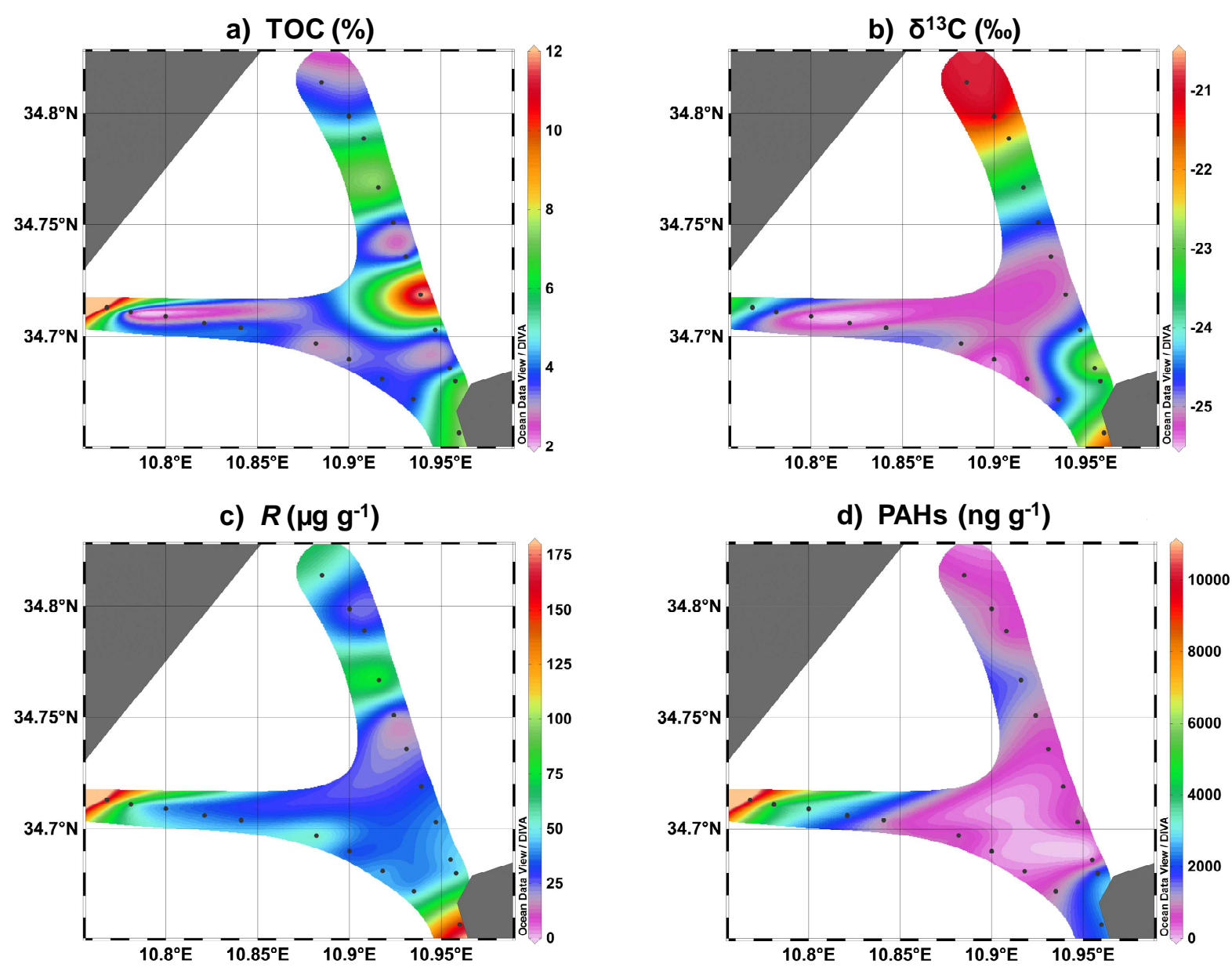

e) R/TOC ( $\left.\mathrm{mg} \mathrm{g}^{-1}\right)$

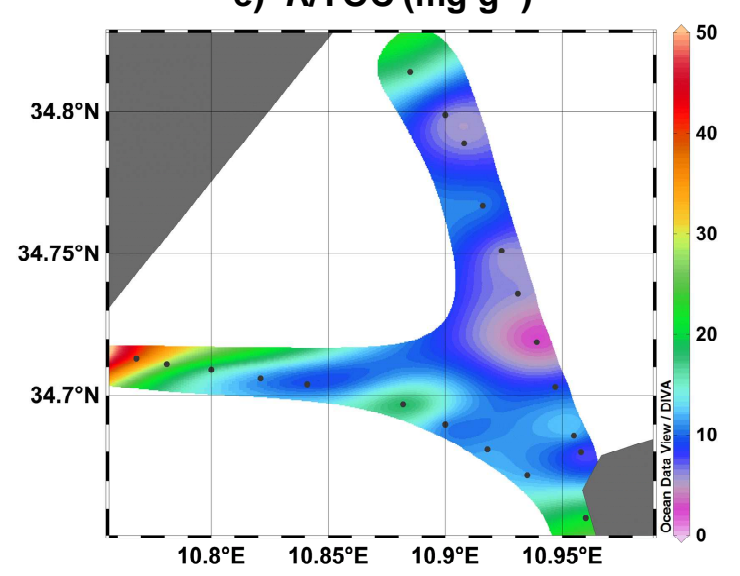

f) $\mathrm{PAH} / \mathrm{TOC}\left(\mu \mathrm{g} \mathrm{g}^{-1}\right)$

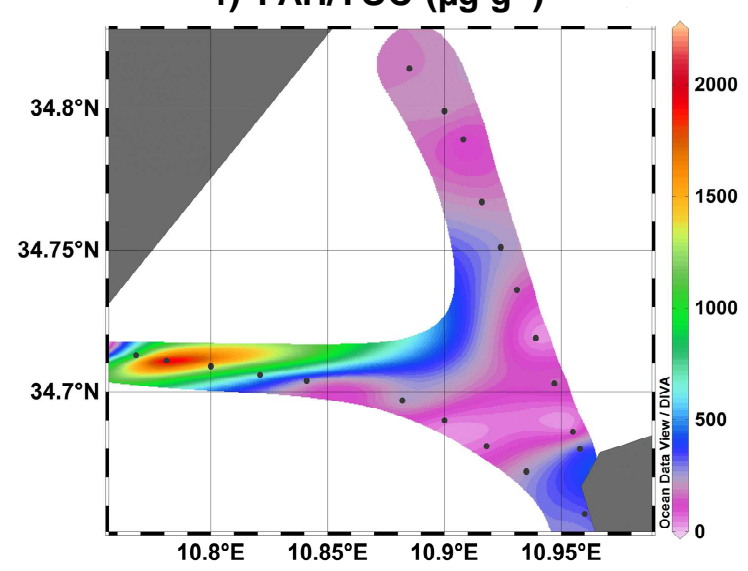

Figure 2 
Relative abundance (\%)

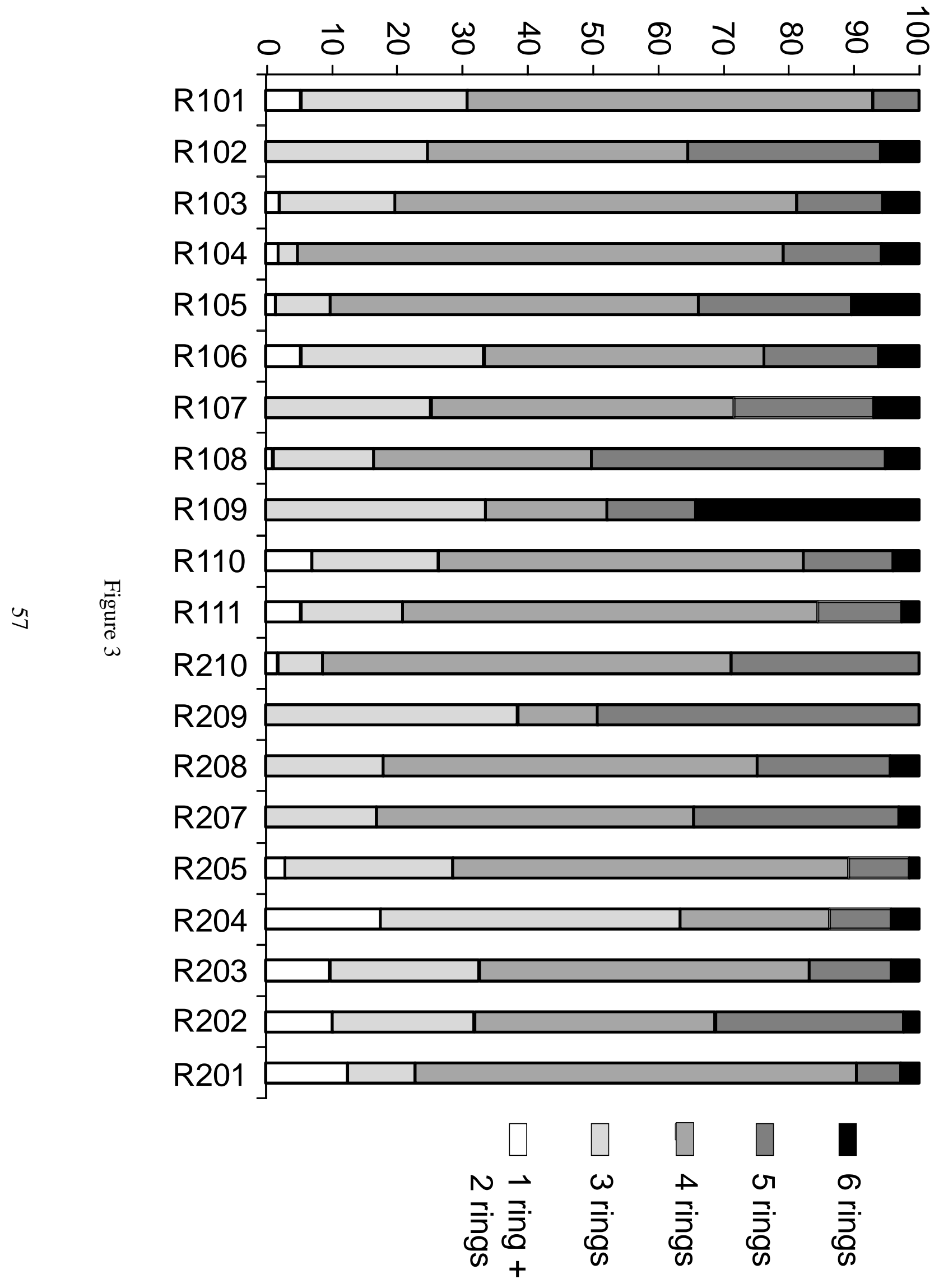


Fuel Grass, coal,

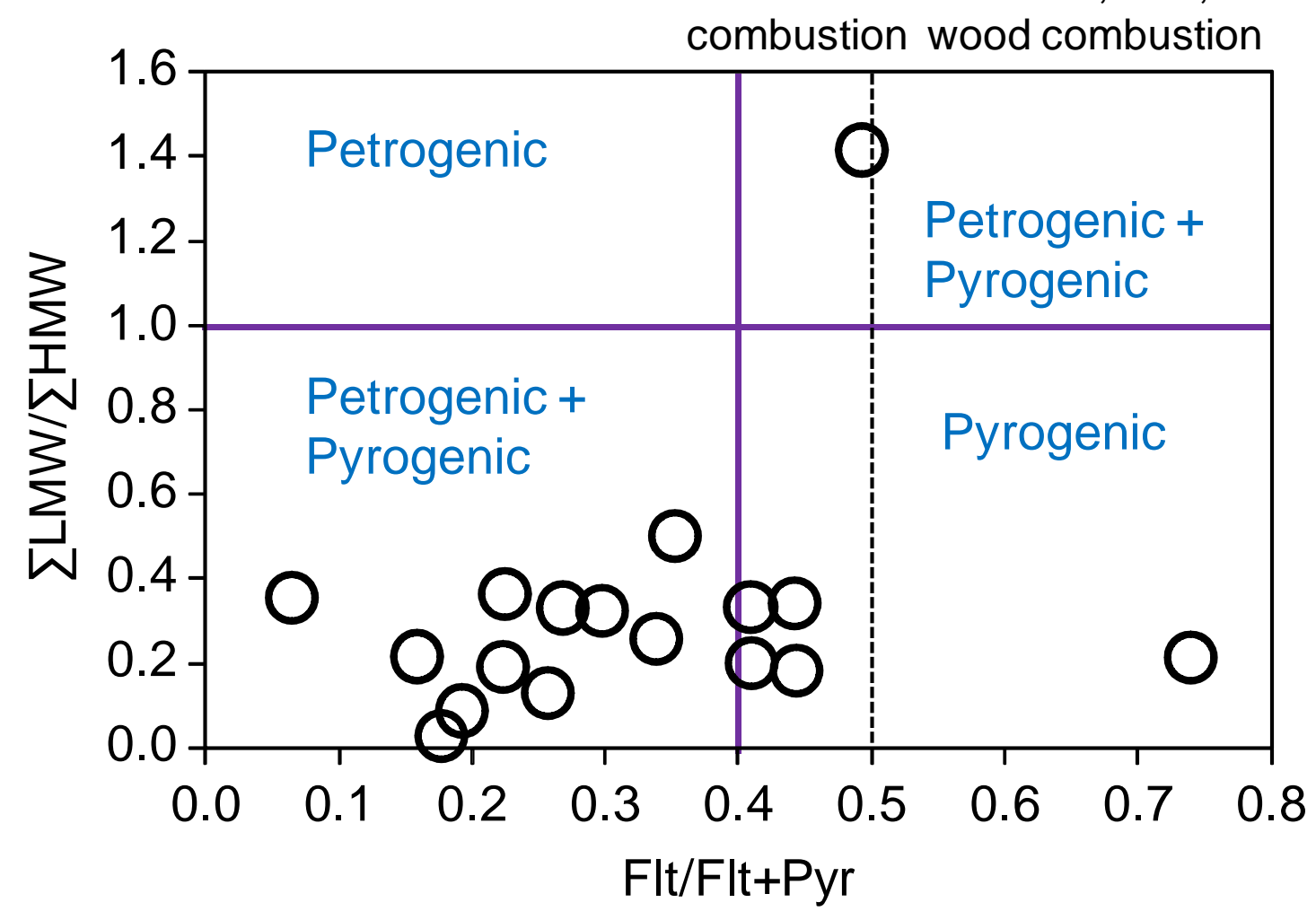

Figure 4 